\title{
Berberine and Coptidis Rhizoma as novel antineoplastic agents: a review of traditional use and biomedical investigations
}

\author{
Jun Tang ${ }^{\mathrm{a}, \mathrm{b}}$, Yibin Feng ${ }^{\mathrm{a}, *}$, Saiwah Tsao ${ }^{\mathrm{c}}$, Ning Wang ${ }^{\mathrm{a}}$, Robert Curtain ${ }^{\mathrm{d}}$, Youwei Wang ${ }^{\mathrm{b}}$ \\ ${ }^{a}$ School of Chinese Medicine, The University of Hong Kong, 10 Sassoon Road, Pokfulam, Hong Kong, \\ PR of China \\ ${ }^{\mathrm{b}}$ College of Pharmacy, Wuhan University, Wuhan 430072, PR of China \\ ${ }^{\mathrm{c}}$ Department of Anatomy, The University of Hong Kong, 21 Sassoon Road, Pokfulam, Hong Kong, PR of \\ China \\ ${ }^{\mathrm{d}}$ Genome Research Center, The University of Hong Kong, 21 Sassoon Road, Pokfulam, Hong Kong, PR \\ of China
}

\footnotetext{
* Corresponding author: Tel.: +852 25890482; fax: +852 28725476

E-mail address: yfeng@hku.hk.
} 


\section{Table of Contents}

Abstract

1. Introduction

2. The history of Huanglian and berberine development as botanic drugs

2.1. The early years of Huanglian development

2.2. The early years of berberine development

2.3. The link between traditional use and modern research of Huanglian and berberine for cancer therapies

3. The pharmacological studies of berberine and Huanglian for cancer therapies

3.1. The cancer cell lines used and antiproliferation properties of berberine

3.2. The underlying mechanisms involved in the cytotoxicity of berberine

3.3. The antiproliferation properties and underlying mechanisms of Huanglian

3.4. Future approaches

4. Genomics and proteomics approaches to study antineoplastic effects of berberine and

\section{Huanglian}

5. Computer-aided molecular design and prediction of cell response to berberine and analogs

6. In vivo studies in animals and humans

\subsection{Huanglian}

6.2. Berberine

6.3. Uncertainties

7. Adverse effects under Huanglian and berberine treatments

\subsection{Huanglian}

7.2. Berberine

8. Concluding remarks 
Acknowledgements

References

Figure captions

Fig. 1-3 


\begin{abstract}
Ethnopharmacological relevance: Coptidis Rhizoma (Huanglian) and its major component, berberine, have drawn extensive attention towards their antineoplastic effects in the recent years. The antineoplastic effects are related to the Chinese Medicine (CM) properties of Huangliang in treating diseases by removing damp-heat and purging fire and counteracting toxicity.

Aim of the review: To trace the long history of the traditional use of Huanglian from folk medicines, especially from Chinese medicine, to recent pharmacological studies of Huanglian and berberine, with an emphasis on their antineoplastic effects and the promise as novel antineoplastic agents.
\end{abstract}

Methods: A total of 7 databases were extensively searched for literature research. The terms and keywords for searching included Huanglian, berberine, Coptis, Coptidis Rhizoma, anticancer, antiinvasion, antimatastasis and mechanism. The papers including ours with studies on anticancer and mechanism, pharmacology and toxicology of Huanglian and/or berberine were focused.

Results: In view of traditional use, the anticancer effects of Huanglian can be ascribed to its CM trait by removing damp-heat, fire and toxicity. From modern biomedical studies, anticancer effects have been demonstrated in both Huanglian and berberine. The underlying molecular mechanisms involve cell cycle arrest, apoptosis induction and antiinflammation. Berberine is an essential anticancer compound in Huanglian. In some studies, the use of Huanglian was shown to be more effective and beneficial than the use of berberine alone. The presence of other protoberberine-type alkaloids in Huanglian might give synergistic effects for the anticancer effects. Berberine also demonstrates effects of antiangiogenesis, antiinvasion and antimetastasis in some cancer cell lines, however, more investigations are required to unravel the underlying mechanisms involved. 
Conclusions: The modern evidences of treating cancer with Huanglian and berberine have a anticancer candidates with low toxicity, berberine and its altered structure, as well as Huanglian and its formulae, will attract scientists to pursue the potential anticancer effects and the mechanisms by using technologies of genomics, proteomics and other advanced approaches. On the other hand, relatively few in vivo studies have been conducted on anticancer effects of Huanglian and berberine. The clinical application of berberine or Huanglian as novel cancer therapeutic agents requires in vivo validations and further investigations of their anticancer mechanisms.

Keywords: Traditional Chinese medicine; Coptidis Rhizoma; Huanglian; Berberine; Antineoplastic agent; mechanisms of anticancer action 
Abbreviations: AP-1: activator protein 1; ATF3: activating transcription factor 3; Bcl-2: B cell lymphoma/leukemia-2; BCD: berberine chloride dihydrate; BCL: berberine hydrochloride; CDK: cyclin-dependent kinase; COX-2: cyclooxygenase-2; FasL: factor associated suicide ligand; GADD153: growth arrest and DNA damage inducible gene 153; GAP: good agricultural practice; HIF: hypoxia inducible factor; Huanglian extract: the water extract of Huanglian; $\mathrm{IC}_{50}$ : fifty percent inhibitory concentration; $\mathrm{ID}_{50}$ : fifty percent inhibitory dose;

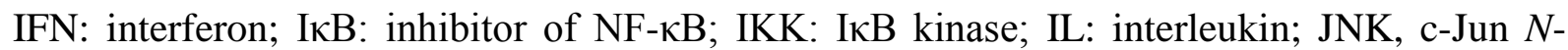
terminal kinase; LOAEL: lowest observed adverse effect level; MAPK: mitogen-activated protein kinase; MDR: multidrug resistance; MLD: minimal lethal dose; MMP: mitochondrial membrane potential; MMPs: matrix metalloproteinases; NAG-1: nonsteroidal antiinflammatory drug activated gene; NCI: National Cancer Institute; NDEA: $N$ -

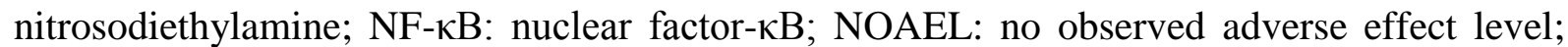
PARP: poly ADP-ribose polymerase; ROS: reactive oxygen species; CM: traditional Chinese medicine; TNF: tumour necrosis factor; Urokinase-type plasminogen activator: u-PA. 


\section{Introduction}

Coptidis Rhizoma (Huanglian in Chinese) has been used for more than two thousand years by CM physicians for treatment of damp-heat syndromes (Chinese Herbals Editor Board, 1999). Berberine (Fig. 1) is an isoquinoline alkaloid commonly used in both China and other countries as a botanic drug which is also a major active compound in Huanglian. It is widely present in the plant kingdom: Berberidaceae Ranunculaceae and Papaveraceae (Felter and Lloyd, 1898; Galle et al., 1994; Lenka et al., 2007). In this review, we focused on Huanglian of Ranunculaceae, because traditional use and ethnopharmacological relevance of Huanglian is link to biomedical investigations of Huanglian and berberine. As specified in the Chinese Pharmacopoeia (The State Pharmacopoeia Commission of the P.R. China, 2005), Huanglian may contain three Coptis species: Coptis chinensis Franch. (Weilian in Chinese), Coptis deltoidea C. Y. Cheng et Hsiao. (Yalian in Chinese) and Coptis teetoides C. Y. Cheng (or Coptis teeta Wall., Yunlian in Chinese) (Fam. Ranunculaceae). There are a few other native Coptis species distributed in other areas of the world which are also used as Huanglian, e.g. Coptis japonica Makino. in Japan (Society of Japanese Pharmacopoeia, 2001) and Coptis trifolia Salisb. (or Goldthread) which were used as domestic medicines in North America (Lloyd and Lloyd, 1887). In China, Weilian has been extensively cultivated in eastern Sichuan and western Hubei provinces under good agriculture practice (GAP) for Chinese Crude Drugs (Xu et al., 2004) (Fig. 2). It is worthwhile to note that the wild Yunlian has been remarked as vulnerable with the conservation status ranking No. 2 in China. Nevertheless, its status as an herbal drug would not be greatly influenced due to a similar extensive cultivation to Weilian in the southwestern part of China. Berberine is an alkaloid component in Huanglian. The recent studies confirmed that Huanglian is a good producer of berberine. Berberine constitutes the most abundant alkaloid in the dried herb (5.20\%-7.69\%, w/w) (Iizuka et al., 2000a; Xu et 
al., 2004). High production of berberine can also be achieved via modifications of metabolic pathways in plants by genetic engineering (Sato et al., 2001).

The main pharmacodynamic properties of berberine and Huanglian have long been recognized on the treatment of intestinal infections including acute gastroenteritis, cholera and bacillary dysentery which can be linked to their antibacterial, antiviral and anti-inflammatory effects (Amin et al., 1969; Subhuti, 2005; Kyoko et al., 2007). The purification of berberine from Huanglian has greatly facilitated investigation studies into the therapeutic applications of Huanglian.

The development of Huanglian and berberine in clinical applications can be broadly divided into several stages:

(a) Early clinical use of Huanglian in CM began at about 2000 years ago in the treatment of diarrhea, eye inflammation and women's abdomen ailments caused by damp-heat, which is still a common use of Huanglian today in CM (Xu et al., 2004; Chen and Gao, 1997a and 1997b).

(b) Early medical uses and development of berberine-containing botanic drugs in North American folk medicine in the treatment of sub-acute and chronic inflammations including gastric disorders, respiratory affections and cancer during the 1800s; but gradually lost their application status in western medicine (Lloyd and Lloyd, 1887; Felter and Lloyd, 1898).

(c) The pre-clinical and clinical studies and development of berberine as a natural antibiotic to treat various bacteria-associated diarrheas in the late 1900s (Dutta and Panse, 1962; Subbaiah and Amin, 1967; Khin et al., 1985; Rabbani et al., 1987).

It is worth highlighting that the antineoplastic activities of berberine have been reported intermittently (Hano, 1959). The initial positive results from these studies together with the information from $\mathrm{CM}$ led to reconsideration of the use of berberine and Huanglian in the 
treatment of cancer diseases. After 1990s, there were more studies on the antineoplastic effects of berberine and Huanglian in diverse cancer cell types, and the underlying mechanisms of the antineoplastic action were also investigated especially on those of berberine. Meanwhile, many other pharmacological benefits have also been reported including lowering of blood cholesterol (Kong et al., 2004), anti-inflammatory effects (Kuo et al., 2004), therapies of experimental colitis (Zhou and Mineshita, 2000) and treatment of diabetes (Zhou et al., 2007) for berberine, hepatoprotective (Ye et al., 2009) and anticachectic effects (Iizuka et al., 2000b) for Huanglian.

In this review, the history of the early development of Huanglian and berberine as botanic drug was traced at first and recent publications on their effects on various cancer cell types and the underlying antineoplastic mechanisms, genomics, proteomics and computer-aided molecular design as well as in vivo studies, general pharmacology and toxicology were then focused in English and Chinese databases. No restrictions regarding the language of publication were imposed, but most relevant studies were published in English and Chinese bibliographies, the electronic literature searches were conducted in the following databases (6 English databases and 1 Chinese database): MEDLINE (1966 to date, via Pubmed), EMBASE (1974 to date), CINAHL (Cumulative Index to Nursing and Allied Health Literature, 1982 to date), AMED (Allied and Complementary Medicine Database, 1985 to date), The Cochrane Central Register of Controlled Trials (CENTRAL),EBM Reviews Full Text - CDSR, ACP Journal Club, and DARE (1991 to date) and China Journals Full-text Database (1915 to date, via CNKI). The following search key words or terms were used: Huanglian, berberine, Coptis, Coptidis Rhizoma, anticancer, antineoplastic mechanisms, genomics, proteomics and computer-aided molecular design as well as in vivo studies, general pharmacology and toxicology. Further manual searches were conducted in our own files as well as in the reference lists of all located articles. After systematic review, we did not find any review 
paper for the anticancer efficacy and safety of Huanglian and berberine until this paper was completed.

All articles were read in full by all authors and data relating to anticancer, genomics, proteomics and computer-aided molecular design as well as in vivo studies, general pharmacology and toxicology of Huanglian and/or berberine and results were extracted by authors. The authors agreed to a consensus on the assessed data and cases of discrepancy would be settled by discussion. Articles which are included in the study had to meet all of the following criteria: (a) experimental studies on anticancer effects of Huanglian and/or berberine; (b) explore underlying mechanisms for anticancer, antiinvasive and antimetastatic effects of Huanglian and/or berberine; (c) new approach such as genomics, proteomics and computer-aided molecular design to studies on anticancer effects of Huanglian and/or berberine; (d) animal studies and clinical trails for anticancer effects of Huanglian and/or berberine; (e) general pharmacological and toxicological effects of Huanglian and/or berberine; (f) traditional use and ethnopharmacological relevance to anticancer effects of Huanglian and/or berberine; (g) articles in English were preferred, but some information which can be only found in Chinese (partially information in $\mathrm{d}$, e and f) were also included. Articles out of the above criteria were excluded. As a result, over 100 peer-reviewed international papers in English as well as 21 peer-reviewed papers or books in Chinese and 5 web information have been cited (136 reference papers in total) This is a first review paper which provided a whole picture and related information on topic of antineoplastic effects of Huanglian and berberine. The potential values of berberine and Huanglian as novel antineoplastic agents for future clinical application are also discussed. The plant sources, biosynthesis, pharmacological actions and phytochemistry of berberine and cultivation of Huanglian can be referred to other review articles published (Li et al., 2008a; Lenka et al., 2007; Yu et al., 2006; Xu et al., 2004). 


\section{The early history of Huanglian and berberine development as botanic drugs}

\subsection{The early years of Huanglian development}

The earliest record of Huanglian can be dated back to Shen Nong's Herbal Classic compiled in the Han Dynasty of China (about A.D. 200), in which Huanglian was regarded as one of the top-grade drugs (tonic and non-toxic) (Xu et al., 2004; Wu et al., 1982). Since then, the use of Huanglian was frequently cited in many other official or un-official medical compilations e.g. Shang Han Lun (Treatise on Cold-induced Febrile Diseases) and Jin Kui Yao Lue (Synopsis of Prescriptions of the Golden Chamber, about A.D. 210, Han Dynasty), Wai Tai Mi Yao (Medical Secrets from the Royal Library, A.D. 752, Tang Dynasty), and Ben Cao Gang Mu (Compendium of Materia Medica, A.D. 1596, Ming Dynasty) (Chen and Gao, 1997a and 1997b). Huanglian is an important component in many traditional Chinese compound formulae (Fufang in Chinese). At least 1,760 Huanglian formulae have been recorded in Chinese Herbals until Song Dynasty (A.D. 1279), and about 108 of which are still in use today (Chen and Gao, 1997a). The well-known and useful ones, such as Xie Xin Decoction from Jin Kui Yao Lue and Huanglian Jiedu Decoction from Wai Tai Mi Yao, have received great attention in evidence-based studies (Feng, 2000; Ohta et al., 2004).

Huanglian can remove damp-heat, fire and counteract toxicity, both of which are related to inflammatory or tumour pathogenesis in CM (Chinese Herbals Editor Board, 1999; Liao et al, 2003). Its traditional use in the treatment of diseases such as stuffiness and fullness of abdomen, diarrhea, vomiting, high fever, fidgetiness and insomnia, eye inflammation, diabetes, carbuncles and sores as specified in Chinese Pharmacopoeia may be results of multiple pharmacological properties including anti-inflammatory and anticancer activities of 
Huanglian. The CM physicians may not have recognized the pathological nature of some diseases as clearly as western medicine. For example, in CM, tumours were described as 'lumps' or 'carbuncles' in the body and were usually believed to be caused by heat-induced toxicity and stagnation of $q i$ and blood. There were indeed some approaches to treat 'tumours' in $\mathrm{CM}$ practices by clearing blood stagnation, lumps, to remove heat and to counteract toxicity (Liao et al, 2003).

In other traditional medicines such as Ayurvedic medicine and early western medicine, in the year of 1800s, the use of berberine-containing botanic drugs was also dominant including the Indian Barberry (Berberis aristata DC., Berberidaceae), European Barberry (Berberis vulgaris L., Berberidaceae), American Hydrastis (Hydrastis canadensis L. or Goldenseal, Ranunculaceae) and Goldthread. The American Hydrastis was largely used both as a medicine and as a coloring material among certain aboriginal tribes of North America. In his first edition of 'Collections for an Essay Toward a Materia Medica of the United States' (1798), B. S. Barton had referred to the Cherokee use of Hydrastis as a cure for cancer, which may represent the oldest recorded use of berberine-containing botanic drugs for cancer treatment. Some homoeopathic practitioners even suggested long and continued use of Hydrastis to retard scirrhus of the breast (Felter and Lloyd, 1898). However, evidence of pre-clinical or clinical studies for these herbs was scanty at that stage. The official use of these botanic drugs gradually diminished in the late 1800 s.

\subsection{The early years of berberine development}

Berberine was firstly isolated and identified as a plant isoquinoline alkaloid (Lenka et al., 2007) in the early nineteenth century (Felter and Lloyd, 1898). In the succeeding years from 1910s to 1960 s, the chemistry and synthesis of berberine was thoroughly studied (Johannes 
and Rose, 1930; Huffman and Miller, 1960) and total synthesis of berberine was achieved in 1969 (Kametani et al., 1969). In the early 1960s, berberine and its salts, such as berberine sulphate, had been demonstrated to be valuable to treat cholera, severe diarrhea and amoebiasis by Indian researchers (Dutta and Panse, 1962; Subbaiah and Amin, 1967). Clinical trials of berberine to treat bacterial diarrhea were reported in 1985 and 1987 (Khin et al., 1985; Rabbani et al., 1987). Berberine itself may not be an effective antibiotic; however, its antimicrobial activity is potentiated by the MDR inhibitor, 5'-methoxyhydnocarpin, which does not have antimicrobial activity on its own (Stermitz et al., 2000). This study showed that Huanglian extract may have higher therapeutic effects than berberine alone and may be the results of synergistic actions of other components present in Huanglian. In China, berberine was isolated and used as a botanic drug in the late 1950s (Subhuti, 2005). The initial clinical application was for treatment of intestinal infections.

The early development of berberine into an anticancer agent was not as promising as its application as a natural antibiotic agent. However, later screening of the Native American anticancer Hoxsey formula, a mixture of botanic drugs containing Barberry (Berberis vulgaris L.), resulted in the identification of berberrubine as the antitumour principal (Patricia et al., 2002; Hoshi et al., 1976). Interestingly, berberrubine is not present as the natural form in the botanic drug (Lenka et al., 2007). It is most likely an in vivo metabolite of berberine that is active for cancer therapy (Zuo et al., 2006).

\subsection{The link between traditional use and modern research of berberine and Huanglian} for cancer therapies

\footnotetext{
Even though there are few indications of Huanglian in early history directly related to treatment of cancer, clues and implications can be derived from traditional uses of Huanglian
} 
in the treatment of diseases with similar symptoms of tumours, as well as basic research by a rapid and uncontrolled formation of abnormal cells, which may mass together to form a growth or tumour, proliferate throughout the body and initiate abnormal growth at other sites. Therefore, anticancer drugs involve pharmacological effects of cytotoxicity, antiproliferation, antiinflammation, cell cycle arrest, apoptosis induction, antiinvasion and antimetastasis etc..

There is no concept of cancer in ancient $\mathrm{CM}$, but some symptoms may relate to cancer. Symptoms such as diarrhea, vomiting, fever, and bleeding are not specific symptoms, cancer may also show similar symptoms. Huanglian, firstly recorded in Shen Nong's Herbal Classic (the oldest herbal compilation in China) to treat diarrhea, inflammation of the eye, and women's abdomen ailments caused by damp-heat, also has long been used for the treatment of these diseases in CM practice (including its formulae). The syndromes with the trait of damp-heat or heat-toxicity can be easily linked to the modern concept of infection or inflammation. Therefore, the early pharmacological study of Huanglian and its formulae were found to be beneficial in anticontagious and antiinflammatory effects. In current studies, many cytokines released by cancer cells can be directly translated to be a similar target of antiinflammatory drugs (Lee et al., 2007a). While the precise mechanisms underlying antitumour effects remain to be investigated, there is increasing evidence showing that Huanglian and/or berberine may inhibit the inflammation-triggered tumorigenesis (Izuka et al., 2000; Kuo et al., 2004; Lee et al., 2007b; Pandey et al., 2008). Inflammation and cancer have been viewed as vicious partners in crime and their relationship has become a hot topic for cancer research (Balkwill and Mantovani, 2001; Coussens and Werb, 2002; Mantovani and Balkwill, 2006; Lu et al., 2006). During inflammation, cytokine, growth factors and free radicals are produced, to activate transcription factors including NF- $\mathrm{kB}$ and downstream cancer-related genes (Hussain and Harris, 2007). The link between anticancer and antiinflammation, can be 
established after antiinflammation, anticachectic, antioxidant, antiproliferation and antiinvasion properties of berberine, Huanglian and/or its formulae have been discovered in vitro and in vivo (Fukuda et al., 1999a, 1999b; Izuka et al., 2000b; Anis et al., 2001; Wang et al., 2002; Jantova et al., 2003; Kuo et al., 2004; Peng et al., 2006; Lee et al., 2007b; Ye et al., 2009, Tsang et al, 2009).

In many modern Chinese herbal books about tumour treatment, Huanglian is chosen as one of the anticancer herbal drugs and is widely used in routine CM practice (Tse, 1977; Qian, 1980; Xu et al, 1997; Chang, 1998; Bo, 2002, Feng et al, 2008). In view of CM, the anticancer effect of Huanglian can be ascribed to one of the CM traits by clearing damp-heat or removing heat and toxicity (Chinese Herbals Editor Board, 1999; Liao et al, 2003), while from biomedical studies, cytotoxic, antiproliferative, antiinflammatory, antiinvasive and antimetastatic effects should all contribute to anticancer effects of Huanglian and berberine (Izuka et al., 2000; Jantova et al., 2003; Kuo et al., 2004; Peng et al., 2006; Lee et al., 2007b, Tsang et al., 2009). In view of historical development, modern studies and clinical applications, anti-inflammatory effect was frequently mirrored in Huanglian application in many classic herbal books, for example, four formulae containing Huanglian (Coptidis Rhizoma) such as Gegen HuanqQin Huanglian decoction (Puerariae Radix, Scutellariae Radix, Coptidis Rhizoma, Glycyrrhizae Radix), Banxia Xiexin decoction (Pinelliae Rhizoma, Scutellariae Radix, Coptidis Rhizoma, Zingiberis Rhizoma, Giensen Radix, Ziziphi Jujubae Fructus, Glycyrrhizae Radix), Huanglian decoction (Coptidis Rhizoma, Pinelliae Rhizoma, Cinnamoni Ramulus, Zingiberis Rhizoma, Ginseng Radix, Ziziphi Jujubae Fructus, Glycyrrhizae Radix) from Shang Han Lun and Jin Kui Yao Lue, Huanglian Jiedu decoction (Coptidis Rhizoma, Scutellariae Radix, Phellodendri Cortex, Gardeniae Fructus) from Wai Tai Mi Yao and Zuo Jin Wan (Coptidis Rhizoma and Evodiae Fructus) from Dan Xi Xin Fa (A.D. 1481, Ming Dynasty) are usually used to treat stomach ache, vomiting, fever, bleeding and 
diarrhea, which are strongly related to infections, inflammations and even cancers (Feng et al, 2008).

As a classic formula, Huanglian Jiedu decoction has been prescribed to treat gastroenteritis, ulcer, acute febrile illnesses and tumours nowadays, in which a pharmacological basis was studied (Sun et al., 2006). This decoction is the aqueous extract of a mixture of four herbs with Huanglian as a major component. All herbs have some similar nature to Huanglian for heat removal, suggesting an integrated anti-inflammatory effect, which may be more easily understood from a traditional view of CM. Our clinical observations have shown that Huanglian-containing formulae were also effective for treating adenoma and carcinoma of the large intestine, Hilar Cholangicarcinoma (Low and Feng, 2004; Feng et al, 2008). It could be hypothesized that Chinese medicines with a similar druggable nature to Huanglian, may also have effective antitumour effects in $\mathrm{CM}$ practice. This idea forms one basis for our future effort to establish links between CM and western counterparts.

In reality regarding $\mathrm{CM}$ practice, practitioners rarely use a pure compound or single herbal drug to treat diseases, but use a combination of single herbs to mix together (so called Fufang, or composite formula). It is a common model for many Chinese medicines studies in recent years, the goal of research is to "dig out" major active single herb(s) in a composite formula for some diseases and further explore active compound(s) in the single herb(s). To the contrary, CM practitioners always integrate traditional use with results derived from modern research. For example, a CM practitioner may use Huanglian combined with other herbs or Huanglian Jiedu decoction to treat cancer, but not berberine. Berberine is one of the active compounds from Huanglian but they are not equal with each other. The effects and mechanisms of Huanglian should include those of berberine; however, berberine would not fully represent that of Huanglian. Thus, Huanglian and berberine in this review have been described separately in order to establish differentiation and their innate correlation. 
Numerous experimental studies of Huanglian and berberine on antitumour, as well as in modern CM practice, have been carried out in recent years, the topic of antiinflammation and anticancer is also a most recent issue. Therefore, Huanglian and berberine are defined in the title as the novel antineoplastic agents. From views of traditional use and pharmacological studies, Huanglian and berberine inhibit inflammation-triggered tumorigenesis, whereby clues have been found from traditional use, but other anticancer effects such as cytotoxicity, antiproliferation, cell cycle arrest, apoptosis, antiinvasion and antimetastasis were discovered in the last ten years, which can be considered as new findings from scientific research.

\section{The pharmacological studies of berberine and Huanglian for cancer therapies}

\subsection{Cancer cell lines used and antiproliferation properties of berberine}

Just as mentioned above, intensive studies on antineoplastic effects of berberine have occurred since the 1990s. Numerous cancer cell lines, either human or murine, have been used to examine the cytotoxic effects of berberine. Berberine could inhibit the growth of many cancer cell lines in vitro at a relatively low $\mathrm{IC}_{50}$. The cancer cell types, which were sensitive to berberine, are broad including both hematological and non-hematological cancer arising from leucocytes, liver, lung, stomach, colon, skin, oral, esophagus, brain, bone, breast and sexual organs (either hormone-dependent or independent). In some cases, the $\mathrm{IC}_{50}$ of berberine was lower than $4 \mu \mathrm{g} / \mathrm{mL}$, which is below the safety limit established by National Cancer Institute (NCI) (Letašiová et al., 2006), indicating the potential of berberine as an antineoplastic drug on human cancer e.g. human cervical cancer, leukemia or colon cancer. Recently, we have confirmed the cytotoxicities of berberine on various cancer cell lines including HONE 1 (nasopharyngeal carcinoma), HK1 (nasopharyngeal carcinoma), HeLa (cervical carcinoma) 
and HepG2 (hepatocellular carcinoma) cancer cell lines in a dose- and time-dependent manner, this confirms the broad spectrum of antineoplastic activity of berberine (unpublished data).

\subsection{Underlying mechanisms involved in the cytotoxicities of berberine}

Recent advances in the study of cell cycle checkpoint controls and DNA repair, have identified key small-molecule inhibitors of the cell cycle relevant to understanding the mechanisms of cancer chemotherapeutic agents (Leland and Michael, 1994; Crews and Shotwell, 2003). Berberine can induce DNA topoisomerase I poisoning and apoptotic cell death (Kettmann et al, 2004a). Many more recent findings, stapled into the antineoplastic story of berberine, are based on the knowledge of cell cycle regulation and the downstream effects or phenotypes related to cell-cycle inhibition, particularly the caspase(s)-dependent apoptosis and associated cell signaling pathways. The intrinsic apoptotic pathways are vital for many normal physiological processes and initiated by a series of apoptotic regulatory and effector proteins such as caspases. Aberrant or dysregulated apoptotic response contributes to the development of cancer (Reed, 2002). There are two main pathways for cell death by triggering the activation of the caspase(s) cascade. One pathway induces apoptosis via interaction of the Fas/FasL system (the extrinsic cell death pathway). Fas is a member of the tumour necrosis factor (TNF) death receptor family, which plays a key role in linking druginduced damage to apoptotic cell processes. Another one is the activation of the mitochondrial pathway (the intrinsic pathway). Studies on treatment of cancer by berberine indicated that apoptosis is involved in the many cancer cell lines examined. The underlying mechanisms for apoptosis induction by berberine, in more or less degree of diversity, are summarized below. More details can be referred to in Fig. 3. 
(a) Cell cycle arrests at $\mathrm{G}_{0} / \mathrm{G}_{1}, \mathrm{G}_{1}$ and/or $\mathrm{G}_{2} / \mathrm{M}$, and coordinated suppression of cyclindependent kinases (e.g., CDK 2, 4, 6) and cyclins (e.g., cyclin B, D, E) (Eom et al., 2008; Mantena et al., 2006a and 2006b; Lin et al., 2006b; Lin et al., 2006c; Kang et al, 2005; Jantova et al., 2003). Our current studies on human nasopharyngeal carcinoma cells (HONE1 cells), suggest that berberine could induce apoptosis via G2 arrest which demonstrated by increased levels of cleaved-PARP, cleaved caspase 3 and cleaved caspase 9 (Tsang et al., 2009). In some cases, the induction of cell cycle arrest was relied on p53 status, for example, $\mathrm{G}_{1}$ arrest was induced in $\mathrm{HCO}$ and $\mathrm{U} 2 \mathrm{OS}$ cells (p53 functional), but $\mathrm{G}_{2} / \mathrm{M}$ arrest in Saos-2 cells (p53 deficient) (Liu et al., 2009a); in others, the cell cycle arrest in $\mathrm{G}_{0} / \mathrm{G}_{1}$ phase was much higher in p53 expressing SK-N-SH cells than those in p53-deficient SK-N-MC cells (Choi et al., 2008), and also the case in p53 positive LNCaP prostate cells than those in p53 negative PC-3 cells (Choi et al., 2009).

(b) The mitochondria/caspase-dependent and/or Fas/FasL signal pathways, evidenced by the altered ratio of anti-apoptotic (Bcl-2 proper, Bcl-xL) and pro-apoptotic (Bax, Bid) members of the Bcl-2 family proteins (Eom et al., 2008; Hsu et al., 2007; Mantena et al., 2006a and 2006b; Lin et al., 2006a; Lin et al., 2006c), loss of mitochondria membrane potential and/or release of cytochrome c (Lin et al., 2007a; Jantova et al., 2007; Hwang et al., 2006; Lin et al., 2006a; Lin et al., 2006c; Mantena et al., 2006a and 2006b), induction of reactive oxygen species (ROS) and/or $\mathrm{Ca}^{2+}$ production (Meeran et al., 2008; Lin et al., 2007a and 2007b; Jantova et al., 2007; Hsu et al., 2007; Lin et al, 2006a; Lin et al., 2006c), activation of Fas or FasL (Hsu et al., 2007; Hwang et al., 2006) as well as activation of a series of caspases, especially the downstream executioner, caspase-3.

(c) Many other cell signaling pathways have also been found to be associated with the anticancer effects of berberine. Hsu et al. (2007) have reported a new mechanism for berberine-induced apoptosis in SW620 human colonic carcinoma cells by targeting the 
redos/ROS pathway and JNK/p38 pathway. Another study on the same cancer type showed that berberine could induce cell growth arrest and apoptosis of HCT-116 and SW480 cells by targeting two pro-apoptotic proteins ATF3 and NAG-1, in which the p53dependent pathway and the PKC, ERK, and GSK-3b pathways were involved, respectively (Rojsanga et al., 2007). Recent research further unraveled a vital role of p53 related pathway in the berberine-mediated tumour suppression. Berberine could induce apoptosis of both A549 (p53+/+) and H1299 (p53-/-) human lung cancer cells, which effect was more pronounced in the A549 in both in vitro and in vivo studies (Katiyar et al., 2009). Similarly, the cells with functional p53 were more susceptible to berberine than the p53-deficient cells, such as in SK-N-SH than SK-N-MC and in LNCaP than PC-3 cells (Choi et al., 2008 and 2009).

(d) Berberine induces apoptosis via positive or negative regulation of various cytokines functioned in cellular network. These include up-regulation of GADD153 (Lin et al., 2007b), inhibition of cyclooxygenase-2 (COX-2) and Mcl-1 (Kuo et al., 2005) and downregulation of nucleolar phosphoprotein nucleophosmin/B23 and telomerase (Wu et al., 1999). A recent study demonstrated that nucleophosmin plays an important role in the regulation of apoptosis as one of Bax chaperons (Kerr et al., 2007). Also, this chaperon was found to be crucial and critical in regulation of the tumour suppressor p53 (Maiguel et al., 2004). GADD153, as a leucine zipper transcription factor, was found to mediate berberine-induced apoptosis in human cervical cancer Ca Ski cells, shown by elevated ratio of $\mathrm{p} 53$ and $\mathrm{Bax} / \mathrm{Bcl}-2$ proteins and increased levels of ROS and $\mathrm{Ca}^{2+}$ release from endoplasmic reticulum (ER). The proposed mechanism is that enforced expression of GADD153 sensitizes the cells to ER stress, which involves down-regulation of Bcl-2 and enhanced oxidant injury (McCullough et al., 2001). 
In addition to direct apoptosis induction, a large number of studies demonstrated that berberine may exert indirect effects against cancers by involving the pro-inflammatory or NFКB pathway (Kuo et al., 2004; Lee et al., 2007b; Pandey et al., 2008), antioxidant defense system (Thirupurasundari, et al., 2009), anti-metastasis pathway (Lin et al., 2008; Kim et al., 2008; Ho et al., 2009a) as well as synergistic effects with other chemotherapeutic agents (Liu et al., 2009b; Peng et al., 2008). The aforementioned berberine-induced ROS generation, may play a key role in modulating inflammatory responses through the inhibition of transcription factors such as NF- $\kappa \mathrm{B}$, which mediates expression of many pro-inflammatory mediators (Lin et al, 2006a; Jantova et al., 2007; Hsu et al., 2007). One recent study dissected the possible role of berberine in the NF- $\kappa$ B signaling pathway (Pandey et al., 2008). Some key components and downstream gene products in this pathway were mediated for berberine-induced apoptotic and anti-inflammatory activities. The mechanism in part, was ascribed to the direct modification of cysteine residue 179 in IKK, resulting in the stabilization of $\mathrm{I}-\kappa \mathrm{B} \alpha$ and suppression of phosphorylation and nuclear translocation of p65, and finally inhibition of NF$\kappa \mathrm{B}$ reporter activity. Moreover, NF- $\kappa \mathrm{B}-$ regulated gene products were also suppressed by berberine including those functional in antiapoptosis (Bcl-xL, Survivin, IAP1, IAP2, and cFLIP), proliferation (cyclin D1), inflammation (COX-2), and invasion (MMP-9). These results established a strong link of enhanced apoptosis induced by TNF- $\alpha$ and chemotherapeutic agents and inhibition of TNF-induced cellular invasion with targeted NF$\kappa \mathrm{B}$ signaling pathway by berberine.

Berberine could inhibit motility and invasion ability of the highly metastatic lung cancer cell line, A549 cells, under non-cytotoxic concentrations via down-regulation of nuclear transcription factors e.g. c-fos, c-jun and NF-kB (Peng et al., 2006). Other explorations for the anti-metastasis function indicated that berberine could inhibit TNF- $\alpha$-induced MMP-9 expression and cell invasion via mediating AP-1 DNA binding activity in MDA-MB-231 
human breast cancer (Kim et al., 2008), induce down-regulation of MMP-1, -2, and -9 and related gene expressions in human SNU-5 gastric cancer cells (Lin et al., 2008), and downregulate $\mathrm{u}-\mathrm{PA}, \mathrm{MMP}-2$ and -9 expressions through MAPK and NF- $\kappa \mathrm{B}$ signaling pathways in human SCC-4 tongue squamous carcinoma cells (Ho et al., 2009). We found that antiinvasion of berberine on HONE1 cell is a different mechanism which through inhibition of RhoA signaling pathway (Tsang et al., 2009). As regards the control of hematopoietic tumor cell, berberine could inhibit the migration of HL-60 cells, primary acute myeloid leukemia (AML) cells and leukemic stem cells (LSCs) induced by chemokine stromal cell-derived factor-1 (SDF-1), showing to be promising for prevention of leukemia (Li et al., 2008b). Berberine could also inhibit AP-1 (a complex of c-fos and c-jun) activation in human hepatoma cells (Fukuda et al., 1999b), oral cancer cells (Kuo et al., 2004) and breast cancer cells (Kim et al., 2008), as well as COX-2 expression in colon cancer cells (Fukuda et al., 1999a).

Several studies showed that berberine could confer synergistic effects against cancer in combination with ER antagonists, irradiation and other chemotherapeutic agents. A recent study by Liu et al. (2009b) demonstrated that the combined treatment of ER antagonists with berberine enhanced the growth inhibitory effect on MCF-7 cells $\left(\mathrm{ER}^{+}\right)$but not on MDA-MB231 cells $\left(\mathrm{ER}^{-}\right)$. Peng et al. (2008) found that 5 and $10 \mu \mathrm{M}$ concentrations of berberine combined with irradiation significantly strengthened the radio-sensitivity on A549 cells, which molecular basis involved the induction of autophagic cell death as well as cell cycle $\mathrm{G} 2 / \mathrm{M}$ arrest (only at $5 \mu \mathrm{M}$ berberine). Arsenic trioxide $\left(\mathrm{As}_{2} \mathrm{O}_{3}\right)$ is usually indicated for the treatment of acute promyelocytic leukemia in vivo, and also induces apoptosis in various tumor cells in vitro. Lin et al. (2008) investigated the co-effects of berberine on $\mathrm{As}_{2} \mathrm{O}_{3^{-}}$ mediated inhibition of cancer cell metastasis using rat and human glioma cell lines. As a result, berberine at $10 \mu \mathrm{M}$ enhanced the $\mathrm{As}_{2} \mathrm{O}_{3}(5 \mu \mathrm{M})$ mediated reduction in motility and invasion of 
glioma cells, which synergistic effects were achieved by the inhibition of PKC- $\alpha$ activity and downstream transcriptional factors, myc and jun, and MT1-MMP and MMP-2 in the PKCmediated signaling pathway involved in cancer cell migration. The synergistic anticancer effect using both $\mathrm{As}_{2} \mathrm{O}_{3}$ and berberine was also found in human neuroblastoma SH-SY5Y cells. The mechanism was based on the mitochondria/caspase-3 dependent signaling pathway (Kim et al., 2007). The synergy researches promote largely the development of multimodality or adjuvant chemotherapy in cancer treatment. However, the idea can be further derived from the principle of $\mathrm{CM}$ practice, in which different combination of the Chinese herbs could be used to treat the different syndromes under various diseases, and the research can be tuned fine by referring to the efficacious or proprietary Chinese formulae. A recent study (Wang et al., 2008) was based on such a formula, Zuo Jin Wan, which has a long-standing use for the treatment of gastrointestinal disorders especially inflammations. Berberine and evodiamine, another natural antitumour alkaloid, composing of the two major active ingredients of the formula, were combined to treat human hepatocellular carcinoma SMMC-7721 cells. The cell apoptosis, cell cycle distribution, and the level of TNF- $\alpha$ were remarkably elevated.

It is worthwhile to note that berberine induced apoptosis in U937 cells without affecting the cell cycle or induction of necrosis in B16 or HeLa cells (Letašiová et al., 2006). Berberine could also antagonize the hypoxia-induced angiogenesis in gastric adenocarcinoma via HIF$1 \alpha$ repression (Lin et al., 2004b). Therefore, the antineoplastic effects of berberine against various cancer cells may involve different mechanisms and is dependent on cell types and concentrations of the agents used.

Based on the above studies and our ongoing research results on berberine, we can conclude that berberine has multiple antineoplastic effects mainly through cytotoxicity, antiproliferation, antiinvasion and antiinflammation mechanisms (Fig. 3). The main mechanism underlying induction of cytotoxicity, growth inhibition of berberine on cancer cells, could be 
mediated through DNA topoisomerase I inhibition and cell cycle arrest which eventually induces apoptosis via the caspase-3 or Fas/FasL signal pathways. Berberine-induced anticancer effects were strongly correlated with its anti-inflammatory properties through cross-talk between different signaling pathways, such as NF- $\kappa \mathrm{B}$ pathway for antiinflammatory effects and caspase-dependent pathways for apoptosis. The mechanisms underlying anti-invasion of berberine are relatively less understood at present. In addition to down-regulate u-PA, MMP-2 and -9 expressions, the signaling pathway involved in cell motility and invasion, such as the RhoA GTPase/ NF- $\mathrm{BB}$ pathway, may be considered (Fig. 3).

\subsection{Antiproliferation properties and underlying mechanisms of Huanglian}

Huanglian has also been used in many anticancer studies in such cancer types as human breast cancer (Li et al., 2000; Kang et al, 2005), human colon cancer (Li et al., 2000), human esophageal cancer (Iizuka et al., 2000a), human gastric cancer (Li et al., 2000), human leukemia (Lin et al., 2004a), human liver cancer (Lin et al., 2004a) and human pancreatic cancer (Hara et al., 2005). We have also reported that Huanglian had the strongest cytotoxicity among a selection of sixteen anticancer Chinese herbs in rat leukemia L-1210 cells (Luo et al., 2002). A much higher inhibitory activity for growth of tumour cells was present in the water extract of Huanglian (or Huanglian extract, the most clinically applied form in $\mathrm{CM}$ ), compared to extracts using other solvents for extraction. Cells treated for 3 hours with $5 \mu \mathrm{g} / \mathrm{ml}$ of the Huanglian extract showed $89 \%$ inhibition, while those treated with ethanol extract showed only $28 \%$ inhibitory activity.

In some studies, the antitumour effects of Huanglian extract were compared with berberine, in which either $\mathrm{IC}_{50}$ or $\mathrm{ID}_{50}$ values were used for assessment of in vitro cytotoxicity (lizuka et al., 2000a and 2003; Lin et al., 2004a; Hara et al., 2005). Iizuka et al. (2000a) found that only 
Huanglian had potent antitumour effects on various esophageal cancer cells among all ingredients of the complex prescription 'Oren-to' (Huanglian Jiedu Decoction), which may be due to its major component, berberine. In another study by Lin et al. (2004a), purified berberine and coptisine (Fig. 1) were shown to be the active components, which were more potent than Huanglian extract against hepatoma and leukaemia cells. However, other studies (Kang et al, 2005; Hara et al., 2005; Iizuka et al., 2003; Li et al., 2000) on human pancreatic and gastric cancer cell lines demonstrated that Huanglian may not necessarily be less potent than berberine alone after normalization to levels of berberine present in the herb extract. The underlying mechanism may be related to genes or cellular pathways resistant to berberine's action that were overcome or regulated by other components in Huanglian (Fig. 1).

On the other hand, Huanglian has also been found to mediate cancer cell apoptosis via similar pathways to berberine, including: a) the regulation of cytokines e.g. up-regulation of IFN- $\beta$ and TNF- $\alpha$ (Kang et al, 2005); b) indirect effects against cancers involving the antiinflammatory pathways. Huanglian could inhibit IL-6 secretion in human esophageal tumour cells (Iizuka et al., 2000b); c) the anti-angiogenesis activity (Wang et al., 2004) and/or d) inhibition of DNA topoisomerase I (Kobayashi et al., 1995). These results have mirrored the diversity of Huanglian against various cancers. Even though the anti-inflammatory effects of Huanglian have demonstrated the art of $\mathrm{CM}$ for cancer therapies by removing heat and toxicity (inflammatory elements in cancerous pathogenesis) and promoting virtue (body immunity) simultaneously, there are still many uncertainties ahead about the underlying mechanisms need to be resolved in the future.

\subsection{Future approaches}


Current studies broadly indicate the involvement of cell cytotoxicity, cell cycle regulatory machinery and apoptosis signaling pathways as targets of anticancer by berberine and Huanglian. The apoptotic cell death induced by berberine and Huanglian in cancer cells may be the result of cell cycle arrest. The detailed molecular mechanisms remain to be elucidated, especially for Huanglian, whose specialty for cancer prevention or therapy has been poorly studied. Similar to the antimicrobial action (Stermitz et al., 2000), synergism may play a key role in treatment of various tumours with Huanglian. The nature and identity of these synergistic components as well as the types for combination however, remain to be unveiled. Furthermore, detailed involvement of pro-apoptotic genes (e.g. $p 53, c-M y c$ and $p R b$ ), antiapoptotic genes (e.g. Bcl-2 gene family members or other cancer-specific genes), the types of cell death (apoptotic, autophagic and necrotic) and the downstream gene transcription (transcriptome analysis), translation (protein expression profile) and microRNAs (miRNA) in cells treated by berberine and Huanglian, remain to be fully clarified. The differential responses of cancer cells and their corresponding normal counterparts to berberine and Huanglian also need to be investigated, since only a few studies have been conducted to compare the cancer cell and non-neoplastic cell and show no insult on normal ones (Meeran et al., 2008; Mantena et al., 2006a; Hwang et al., 2006). It is encouraging to see that some transcriptional or regulatory factors, receptors as well as non-apoptosis cell death pathways are being identified as new targets of berberine and/or Huanglian such as the aforementioned pro-apoptotic proteins, nucleophosmin, HIF-1 $\alpha$, COX-2 and GADD153, RhoA/NF-kB signaling pathway and autophagic cell death, leading to a better understanding of the underlying mechanisms.

4. Genomics and proteomics approaches to study antineoplastic effects of berberine and Huanglian 
Very few genomics (or more exactly transcriptome analysis) and proteomics approaches have been carried out to investigate the inhibitory effects of Huanglian and berberine on tumour cells. With a microarray-based mRNA approach, Efferth et al (2005) had examined the expression values of $31 \mathrm{ABC}$ transporter genes and another 9,706 genes from $60 \mathrm{NCI}$ cancer cell lines treated with berberine. Twenty genes were identified that significantly predicted sensitivity or resistance of the cell lines to berberine and expression of $8 \mathrm{ABC}$ transporters correlated well with the $\mathrm{IC}_{50}$ values for berberine. Among them, the $\mathrm{ABCB} 1$ (MDR1) gene was validated to confer resistance to berberine in CEM/VCR1000 leukemia cells. Another study (Hara et al, 2005) used 8 human pancreatic cancer cell lines which examined the $\mathrm{ID}_{50}$ of Huanglian. By hierarchical cluster analysis, the investigators identified 27 Huanglian-related genes using DNA microarray data from 12,600 genes and suggested that berberine can account for the majority of the anti-proliferation activity of Huanglian. Previously, gene expression patterns explored by the same group using pancreatic cancer cells and oligonucleotide microarrays, also led to the identity of 12 genes from approximately 11 , 000 genes showing a strong correlation $\left(r^{2}>0.81\right)$ with the $\mathrm{ID}_{50}$ values of both agents, suggesting that these genes are associated with the anti-proliferative activity of berberine in Huanglian (Iizuka et al., 2003). These genomic approaches help to identify novel marker genes and cell signaling pathways affected by berberine and Huanglian.

Similar to mRNA expression based on transcriptome analysis, proteomics also provides high-throughput analysis of expressed proteins in berberine treated cells in examining or predicting cell response to many external stimulus. However, this may not correlate with changes in mRNA levels due to complicated protein-protein or protein-DNA interactions (Fell, 2001). A study conducted by Tan et al. (2006) investigated differential protein expression in a human liver cancer cell line, HepG2, after berberine treatment. The results showed a network 
of proteins involved in the MAPK phosphor-relay systems, metabolism, and regulation of cell cycle and DNA damage responses. This work serves as a paradigm for further studies on the molecular mechanisms of berberine or Huanglian against many tumours.

\section{Computer-aided molecular design and prediction of cell response to berberine and analogs}

Several studies have reported the structure and activity of berberine as a small molecule ligand. In one study, the X-ray crystal structures of the human topoisomerase I-DNA cleavable complex, combined with a Sybyl software package, have been used to analyse the properties of berberine as a potent topoisomerase I poison for a next generation anticancer drug (Kettmann et al, 2004a). Another study using NCI database by COMPARE analysis, investigated the responses of 60 cancer cell lines to berberine (the $\mathrm{IC}_{50}$ values) and examined the correlation to another 43,177 compounds included in the database, in order to establish the molecular determinants of response of tumour cells to berberine. Preliminary research results were able to correlate the sensitivity or resistance of the cell lines with berberine, based on microarray-mRNA expression assays (Efferth et al, 2005). Recent progress in structural and functional aspects of telomeric G-quadruplex and telomerase, demonstrated that the preferable chemicals to telomerase activity (another promising near-universal anticancer target) could be designed with high selection, specificity and fewer side effects. One such research, targeting telomerase, found that the 9-substituted derivatives of berberine displayed a stronger binding affinity with the telomeric G-quadruplex and corresponding high inhibitory effect against telomerase activity (Zhang et al., 2007). These molecular modeling studies, have enabled exploration of the actions of small anticancer drugs such as berberine in a more precise and selective fashion. 


\title{
6. In vivo studies in animals and humans
}

\author{
6.1. Huanglian
}

As aforementioned, Huanglian can remove damp-induced heat and counteract toxicity, both of which are related to tumour pathogenesis in CM (Chinese Herbals Editor Board, 1999; Liao et al, 2003). Huanglian is now recorded in some anticancer Chinese herbal books (Bo et al, 2002; $\mathrm{Xu}$ et al, 1997; Tse, 1977) and can be used in daily CM clinical practice for cancer treatment. Huanglian and Huanglian formulae (with Huanglian as the main herb) such as Huanglian Jiedu decoction have been described as anticancer agents and used for treating pancreas cancer, breast cancer, liver cancer and colon cancer in clinical Chinese herbal books (Qian, 1980; Chang, 1998). Owing to the potential in vitro results in the treatment of cancers, a phase I dose escalation study of Huanglian in patients with advanced solid tumours is currently ongoing at Memorial Sloan-Kettering Cancer Center (ClinicalTrials.gov, 2009).

An in vivo study showed that Huanglian Jiedu decoction can significantly inhibit the $\mathrm{H} 22$ tumour in mice in a dose-dependent manner, all of the Huanglian Jiedu decoction in different dosage groups could highly inhibit the proliferation of 4 human cancer cell lines: Swille, SPCA-1, SGC-7901 and MCF-7 (Sun et al., 2006).

\subsection{Berberine}

The effect of berberine on WEHI-3 leukemia cells in vivo was examined. The results showed that Mac-3 and CD11b markers, which indicate inhibition of differentiation of macrophages and granulocytes precursors, were down-regulated after treatment. There was no 
affect on the expression of CD14 marker, except for the CD19 marker, which indicated promotion of differentiation of the B-cell precursors. The spleen sizes from mice treated with berberine, were found to be lower when compared to those from untreated animals (Yu et al., 2007). The treatment with berberine was also found to be able to inhibit the leukemia growth induced by Friend murine leukemia virus in BALB/c mice and further support its potential for virally induced cancer chemoprevention (Harikumar et al., 2008). On the other hand, in vivo studies involving solid tumours were usually conducted with the murine xenograft animal models. The anticancer activity of berberine was examined in a transplantable B16 tumour system at a range of doses from $1 \mathrm{mg} / \mathrm{kg}$ to $10 \mathrm{mg} / \mathrm{kg}$. Significant reduction of tumour volume was observed on day 16 at doses of 5 and $10 \mathrm{mg} / \mathrm{kg}$. The dose of $1 \mathrm{mg} / \mathrm{kg}$ stimulated increase of tumour mass, but other tested concentrations, 5 and $10 \mathrm{mg} / \mathrm{kg}$, reduced the tumour mass (Letašiová et al., 2005a). In other studies, the treatment with berberine $(10 \mathrm{mg} / \mathrm{kg}$ of body weight) inhibited significantly the human tongue cancer growth in xenograft mice, showing the promise for tongue cancer prevention in clinic (Ho et al., 2009b). The oral administration of berberine inhibited the growth of A549 (p53+/+) and H1299 (p53-/-) lung tumours inoculated subcutaneously in athymic nude mice, especially more effective in A549 tumour xenograft mice (58\% tumour volume reduction vs. $35 \%$ in $\mathrm{H} 1299$ at a dose of $100 \mathrm{mg} / \mathrm{kg}$ ) (Katiyar et al., 2009). Berberine also strongly suppressed the growth of human prostate cancer xenograft in mice, in which LNCaP xenografts with p53 expression were more easily affected by apoptotic cell death than those inoculated with p53-deficient PC-3 cells (Choi et al., 2009). Furthermore, the chemomodulatory activity of Alstonia scholaris extract (ASE) was investigated in combination with berberine hydrochloride (BCL) on Ehrlich ascites carcinoma-bearing mice (Jagetia and Baliga, 2004). The tumour-bearing animals were injected with various doses of ASE, and $8 \mathrm{mg} / \mathrm{kg}$ of $\mathrm{BCL}$ (one-fifth of the $\mathrm{LD}_{50}$ ) was combined with different doses of ASE (60-240 mg/kg). The combination of $180 \mathrm{mg} / \mathrm{kg}$ of 
ASE with $8 \mathrm{mg} / \mathrm{kg}$ of BCL showed the greatest antitumour effect; the number of tumour-free and 40.5 days, respectively, compared to the non-treated group. Similarly, $180 \mathrm{mg} / \mathrm{kg}$ of ASE in combination with different doses of BCL $(2-12 \mathrm{mg} / \mathrm{kg})$, showed a dose-dependent increase in anticancer activity up to $8 \mathrm{mg} / \mathrm{kg}$ of BCL. The best effect was observed when $180 \mathrm{mg} / \mathrm{kg}$ of ASE was combined with 6 or $8 \mathrm{mg} / \mathrm{kg}$ of BCL, where an increase in antineoplastic activity was observed. Clinically, ionizing radiation is one of most commonly used strategies for lung cancer therapies, however, how to maintain the radio-sensitizing effects still remains a challenge. In the study by Peng et al. (2008), berberine being given intraperitoneally at 2.0 $\mathrm{mg} / \mathrm{kg}$ twice weekly in combination with irradiation almost abridged the growth of implanted Lewis lung carcinoma in C57BL/6 mice. The mechanism was in a good agreement with the autophagy-mediated tumor diminishment. The results verified the synergistic cytotoxic effect of berberine and irradiation.

Berberine was also found to significantly inhibit carcinogenesis induced by 20methylcholanthrene (200 $\mu \mathrm{g} / 0.1 \mathrm{~mL} /$ mouse) or $N$-nitrosodiethylamine (NDEA; 0.02\% NDEA in distilled water, $2.5 \mathrm{~mL} / \mathrm{animal}$ by gavage, five days a week for 20 weeks) in a dosedependent manner using mice and rats. Administration of berberine $(0.5,2.5$ or $5.0 \mathrm{mg} / \mathrm{kg})$ could significantly reduce the incidence of tumour in animals after injection of 20methylcholanthrene, with increased life spans observed compared with controls. When berberine $(10,25$ or $50 \mathrm{mg} / \mathrm{kg})$ was administered simultaneously with NDEA, the markers of liver injury (liver weight, gamma-glutamyl transpeptidase activity and glutathione $S$ transferase level) were reduced significantly compared with animals treated with NDEA alone. Similar decreases in the serum levels of lipid peroxide, bilirubin and glutamate pyruvate transaminase were also noted. Morphology of liver tissue and levels of marker enzymes indicated that berberine offered protection against chemical carcinogenesis (Anis et al., 2001). 


\subsection{Uncertainties}

Although Huanglian has been used clinically for treating cancers in China, a gateway to comprehensive clinical trial is just on the very preliminary stage (ClinicalTrials.gov, 2009). On the other hand, a note of caution was observed in a study using berberine and Huanglian to treat hepatoma cancer cells in which high cytotoxic effect in peripheral blood mononuclear cells was observed (Lin et al., 2004a). In addition, antagonistic actions of berberine on other chemotherapeutic agents e.g. paclitaxel-induced cytotoxicity in oral (OC2), gastric (SC-M1) and colon (COLO 205) cancer cells was also observed through up-regulation of MDR1 (Lin et al., 1999), which may compromise the actions of other chemotherapeutic agents. These issues should be validated in in vivo studies comparing with berberine, Huanglian and other chemotherapeutic agents.

\section{Adverse effects under Huanglian and berberine treatments}

\subsection{Huanglian}

According to unpublished data, Huanglian has no major side effects after being p.o. administrated $200 \mathrm{mg} / \mathrm{kg}$ daily for three weeks. The acute toxicity study showed that $\mathrm{LD}_{50}$ of Huanglian was $4.89 \mathrm{~g} / \mathrm{kg}$ in mice by gavage (Qiu et al., 2004a); and at a daily dose of $3 \mathrm{~g} / \mathrm{kg}$ for 8 days Huanglian could markedly elevate AST level in serum (Qiu et al., 2004b). There were some reports suggesting that Huanglian may cause haemolytic jaundice and nuclear jaundice of the newborn infants with glucose-6-phosphate dehydrogenase deficiency (Yang and Gao, 1996). However, neither experimental studies nor clinical investigations found any 
related evidence on the offsprings after administration directly or through pregnant mothers with Huanglian or Huanglian formulae. In contrary, Huanglian is commonly used as a single drug or Huanglian formulae in CM to prevent infections in newborn infants. Prescriptions of Huanglian are not prohibited in Chinese medicines for pregnant women (Gao et al, 2002).

\subsection{Berberine}

Berberine sulfate also has not caused any histopathological changes in rat tissues and organs when administered for 6 weeks in $500 \mathrm{mg} / \mathrm{kg}$ daily oral doses (Kowalewski et al., 1975). The $\mathrm{LD}_{50}$ values for berberine have showed great variation among different species, or may be dependent on administrative routes. The i.v. administration of berberine and its analogs may induce higher toxic effects than p.o.. In an earlier study, MLD of BCL in s.c. administration to mice was found to be $10 \mathrm{mg} / \mathrm{kg}$, while BCL was not toxic by oral administration in mice (Aoyama, 1951). In another study, the $\mathrm{LD}_{50}$ of berberine sulfate was $24.3 \mathrm{mg} / \mathrm{kg}$ in mice under i.p. administration but $392 \mathrm{mg} / \mathrm{kg}$ on oral route (Sabir and Bhide, 1971). In rats, $\mathrm{LD}_{50}$ of berberine sulfate has been reported more than $1 \mathrm{~g} / \mathrm{kg}$ on p.o., 88.5 $\mathrm{mg} / \mathrm{kg}$ on i.p., and $14.5 \mathrm{mg} / \mathrm{kg}$ on i.m. administration (Kowalewski et al., 1975). On the other hand, $\mathrm{LD}_{50}$ for i.p. administration to mice and rats were found to be $30 \mathrm{mg} / \mathrm{kg}$ and $205 \mathrm{mg} / \mathrm{kg}$ respectively, allowing mice to be approximately six-fold more sensitive to toxicity from berberine (Registry of the Toxic Effects of Chemical Substances, 1998). Berberine chloride dihydrate (BCD) was evaluated for developmental toxicity in rats and mice (Jahnke, et al., 2006). In this study, there were no maternal deaths, however adverse effects were noted in maternal rat, but not in fetus. The lowest observed adverse effect level (LOAEL) in maternal rat remained at $531 \mathrm{mg} / \mathrm{kg} /$ day based on the feeding study and developmental toxicity. The no observed adverse effect level (NOAEL) was raised to $1000 \mathrm{mg} / \mathrm{kg} / \mathrm{day}$ BCD based on the 
gavage study. In mice, $33 \%$ of the treated females died. Surviving animals had increased water intake, and average fetal body weight per litter decreased 5-6\%, with no change in live litter size. Maternal toxicity LOAEL remained at $841 \mathrm{mg} / \mathrm{kg} / \mathrm{day} \mathrm{BCD}$, based on increased water consumption, while developmental toxicity LOAEL was raised to $1000 \mathrm{mg} / \mathrm{kg} / \mathrm{day}$ BCD based on decreased fetal body weight. Developmental toxicity NOAELs in both rat and mice studies are about 500 times higher than the amount of berberine taken for dietary supplements (e.g., goldenseal) by humans and about 60-100 times higher than a pharmacologic dose.

The most common adverse responses of berberine include constipation, laxative, anaphylaxis and other skin allergies such as dermatitis and rashes, and overdose may cause respiratory and circulatory system problems. Furthermore, berberine could displace bilirubin from serum-binding proteins, causing jaundice, kernicterus, and brain damage in infants (Bateman et al., 1998; Chan, 1993, 1994). Therefore, exposure of pregnant women to berberine is not recommended because it may lead to jaundice and kernicterus in the fetus (Chan, 1993).

\section{Concluding remarks}

Huanglian is a Chinese medicinal herb and berberine constitutes its major active component. It has been used clinically in certain $\mathrm{CM}$ formulae for treating inflammatory diseases and cancers. There are three distinct medicinal agents related to Huanglian which are used in CM, that is, Chinese composite formulae containing Huanglian (e.g., Huanglian Jiedu decoction), the single herb Huanglian, and single compound berberine, however, their physiochemical nature, pharmacological profiles and clinical indications in CM are somewhat similar to each other. Huanglian is the main active herb of Huanglian Jiedu decoction, both of 
which contain the main active principal, berberine. Hence, in the standpoint of chemistry, in that berberine is the major active compound against cancer, all three agents are strongly correlated. Actually, their clinical uses in modern CM practice have largely been benefited from basic research achievements on berberine. In return, the clinical successes further promote research activities and the understanding of molecular mechanisms as addressed above. In this review, recent progresses in research of berberine and Huanglian against cancers are highlighted.

In $\mathrm{CM}$, there were no direct claims of Huanglian to cancer therapies in early history. However, there are many indications of anti-tumour effects in Chinese herbs with similar core properties to Huanglian such as clearing damp-heat, fire and toxicity (they can be conceived as characteristics of inflammatory diseases nowadays) and their perspective uses in treatment of diseases with tumour symptoms, which can be derived from both traditional knowledge and modern basic research. The early development of berberine and Huanglian as botanic drugs to treat infections and inflammations may also be helpful to understand more clearly their potential value as anticancer agents. The positive results of carcinostatic research of berberine-containing plants in early 1900s and the purification of berberine have encouraged researchers to explore antineoplastic properties of Huanglian and berberine in conventional approaches. Even though many other pharmacological effects have been reported in berberine and Huanglian including lowering of blood cholesterol and blood pressure and decrease of blood glucose, the potential use of berberine and Huanglian as antineoplastic agents has triggered new excitement and enthusiasm in investigations. The relatively low toxicities at therapeutic level for both Huanglian and berberine also show additional benefit for their further development.

Berberine is an essential anticancer compound in Huanglian. However, it is interesting to note in some studies that Huanglian extract may be more effective than berberine alone (Hara 
et al., 2005; Iizuka et al., 2003; Li et al., 2000). One explanation is that other components in Huanglian may act synergistically with berberine (Fig. 1). The identities of these components and their mode of action are still unknown. This would suggest that berberine alone might not fully represent the therapeutic properties of Huanglian used in CM practice. This point is also best illustrated by the use of Huanglian formulae (with the main herb as Huanglian) in CM, in which various ingredients follow the rule of drug synergism and compatibility (Qiu, 2007). The synergy research in combination with berberine and other typical tumour-killing approaches have drawn a large attention so far, however, it may be greatly promoted with the full understanding of the intrinsic principle implied in CM.

The anticancer effects of berberine and Huanglian mainly involve cytotoxicity, antiproliferation and anti-invasion. It is clear that berberine is able to inhibit the growth of various types of cancer cells by inhibiting DNA topoisomerase I, inducing cell cycle arrest and apoptosis mainly through caspase-3 or Fas/FasL signaling pathways. Current studies also demonstrate that berberine-induced anticancer effects are strongly correlated with antiinflammatory properties through cross-talk between different signaling pathways targeted, such as NF- $\kappa \mathrm{B}$ pathway for anti-inflammatory effects and caspase-dependent pathways for apoptosis. This evidence may further establish a link with the art of CM to treat cancers from its original standpoint by removing heat and toxicity (inflammatory elements in cancerous pathogenesis). In addition to down-regulation of u-PA and matrix metalloproteinases (MMPs) expression, the mechanism underlying anti-angiogenic, anti-invasive and anti-metastatic effects of berberine is less understood at present, which warrant further investigation. We propose that inhibition of the RhoA GTPase/NF- $\kappa \mathrm{B}$ pathway may be involved anti-invasive effect of berberine according to our current study. In vivo studies in animals will also be needed to validate the in vitro studies. 
All in all, most studies and discoveries on the anticancer properties of berberine and Huanglian have just been conducted and found during the last ten years, many more details for their clinical potential, such as cancer types, molecular targets, dosages, and indication on different individuals, remain uncovered. Therefore, further studies are still warranted in order to transfer the knowledge for antineoplastic actions of berberine and Huanglian to clinical applications by using advanced approaches.

\section{Acknowledgements}

The study was financially supported by grants from the research council of the University of Hong Kong (Project Code: 10400413), the University Grants Committee (UGC) of Hong Kong (Project Code: 764708M), the Pong Ding Yueng Endowment Fund for Education and Research in Chinese-Western Medicine (Project Code: 20005274) and the GovernmentMatching Grant Scheme (4th Phase, Project Code: 20740314). This study is also a part of National Program for Key Science and Technology Project for the $11^{\text {th }}$ Five-Year Plan (Project Code: 2006BAI06A15-4) supported by Department of Science and Technology of P. R. China.

\section{References}

Amin, A.H., Subbaiah, T.V., Abbasi, K.M., 1969. Berberine sulfate: antimicrobial activity, bioassay, and mode of action. Canadian Journal of Microbiology 15, 1067-1076.

Anis, K.V., Rajeshkumar, N.V., Kuttan. R., 2001. Inhibition of chemical carcinogenesis by berberine in rats and mice. Journal of Pharmacy and Pharmacology 53, 763-768. 
Aoyama, H., 1951. Antibacterial and toxic effects of berberine hydrochloride. Japanese Journal of Pharmcology \& Chemistry 23, 93-96.

Balkwill, F., Mantovani, A., 2001. Inflammation and cancer: back to Virchow? Lancet 357, 539-545.

Bateman, J., Chapman, R.D., Simpson, D., 1998. Possible toxicity of herbal remedies. Scottish Medical Journal 43, 7-15.

Bo, Q.M., 2002. A selection of the illustrated Chinese anticancer herbal medicines (Kang zhong liu Zhong cao yao jing xuan yuan se tu pu). Shanghai Science and Technology Press, Shanghai, p. 254. (Chinese)

Chan, E., 1993. Displacement of bilirubin from albumin by berberine. Biology of the Neonate 63, 201-208.

Chan, T.K.Y., 1994. The prevalence, use, and harmful potential of some Chinese herbal medicines in babies and children. Veterinary \& Human Toxicology 36, 238-240.

Chang, M.Y., 1998. Applicable Anti-cancer Prescriptions (Shi Yong Kang Ai Fang Ji). China Medical Press, Beijing, p.197. (Chinese)

Chinese Herbals Editor Board, the State Administrative Bureau of Chinese Medicine of China, 1999. Chinese Herbals (Zhong Hua Ben Cao). Shanghai Science and Technology Press, Shanghai, pp. 213-223. (Chinese)

Chen, F.X., Gao, X.S., 1997a. Huanglian-containing prescriptions and dispensations in ancient Chinese literatures. Chinese Traditional Patent Medicine 19, 40-41. (Chinese)

Chen, F.X., Gao, X.S., 1997b. Huanglian single prescriptions and Huanglian therapy. Chinese Traditional Patent Medicine 19, 36-37. (Chinese)

Choi, M. S., Yuk, D.Y., Oh, J.H., Jung, H.Y., Han, S.B., Moon, D.C., Hong, J.T., 2008. Berberine inhibits human neuroblastoma cell growth through induction of p53-dependent apoptosis. Anticancer Research 28, 3777-3784. 
Choi, M. S., Oh, J.H., Kim, S.M., Jung, H.Y., Yoo, H.S., Lee, Y.M., Moon, D.C., Han, S. B., Hong, J.T., 2009. Berberine inhibits p53-dependent cell growth through induction of apoptosis of prostate cancer cells. International Journal of Oncology 34, 1221-30.

ClinicalTrials.gov., 2009. In: Huanglian (Chinese Herb) in treating patients with advanced solid tumors. http://clinicaltrials.gov/ct2/show/NCT00014378. Visiting time: May, 2009.

Coussens, L.M., Werb, Z., 2002. Inflammation and cancer. Nature 420, 860-867.

Crews, C.M., Shotwell, J.B., 2003. Small-molecule inhibitors of the cell cycle: an overview. Progress in Cell Cycle Research 5, 125-133.

Dutta, N.K., Panse, M. V., 1962. Usefulness of berberine (an alkaloid from Berberis aristata) in treatment of cholera (experimental). Indian Journal of Medical Research 50, 732-738.

Efferth, T., Chen, Z.P., Kaina, B. and Wang, G., 2005. Molecular determinants of response of tumor cells to berberine. Cancer Genomics \& Proteomics 2, 115-124.

Eom, K.S., Hong, J.M., Youn, M.J., So, H.S., Park, R., Kim, J.M., Kim, T.Y., 2008. Berberine induces G1 arrest and apoptosis in human glioblastoma T98G cells through mitochondrial/caspases pathway. Biological \& Pharmaceutical Bulletin 31, 558-562.

Felter, H.W., Lloyd, J.U., 1898. In: King’s American Dispensatory 1898, Hydrastis (U.S.P.)Hydrastis. http://www.henriettesherbal.com/eclectic/kings/hydrastis.html. Visiting time: May, 2009.

Fell, D.A., 2001. Beyond genomics. TRENDS in Genetics 17, 680-682.

Feng, S.J., 2000. Experimental and clinical studies of Banxia Xiexin decoction in the prevention of early stage of gastricarcinoma. Chinese Traditional Patent Medicine 22, 576577. (Chinese)

Feng, Y., Luo, W.Q., Zhu, S.Q., 2008. Explore new clinical application of Huanglian and corresponding compound prescriptions from their traditional use. China Journal of Chinese Materia Medica (Zhongguo 33, 1221-1225. (Chinese, abstract in English) 
Fukuda, K., Hibiya, Y., Mutoh, M., Koshiji, M., Akao, S., Fujiwara, H., 1999a. Inhibition by berberine of cycloxygenase-2 transcriptional activity in human colon cancer cells. Journal of Ethanopharmacology 66, 227-233.

Fukuda, K., Hibiya, Y., Mutoh, M., Koshiji, M., Akao, S., and Fujiwara, H., 1999b. Inhibition of activator protein 1 by berberine in human hepatoma cells. Planta Medica 65, 381-383.

Galle, K., Blodt, S., Wagner, H., 1994. TLC and HPLC detection of alkaloids in Mahonia aquifolium and related plants. Deutsche Apotheker Zeitung 134, 35.

Gao, X.S., Chen, F.X., Yang, S.Y., Pi, X.X., Li, J.R., Lin, L., Liu, Y., Wang, X.H., Yan, M,Z., Gao, Y.N., Wang, C.S., Ye, A.L., Liu, K.L., Jiang, G.F., Huang, F.S., Liu, X.L. 2002. The comprehensive study on the Huanglian-induced haemolytic jaundice and its prevention. China Journal of Chinese Materia Medica 27, 70-71. (Chinese)

Hano, K., 1959. The carcinostatic effects of some plant components and their related compounds. Acta-Unio Internationalis Contra Cancrum 15 (Suppl 1), 122.

Hara, A., Iizuka, N., Hamamoto, Y., Uchimura, S., Miyamoto, T., Tsunedomi, R., Miyamoto, K., Hazama, S., Okita, K., Oka, M., 2005. Molecular dissection of a medicinal herb with anti-tumor activity by oligonucleotide microarray. Life Sciences 77, 991-1002.

Harikumar, K.B., Kuttan, G., Kuttan, R., 2008. Inhibition of progression of erythroleukemia induced by Friend virus in BALB/c mice by natural products-berberine, curcumin and picroliv. Journal of Experimental Therapeutics and Oncology 7, 275-284.

Ho, Y.T., Yang, J.S. Li, T.C., Lin, J.J., Lin, J.G., Lai, K.C., Ma, C.Y., Wood, W.G., Chung, J.G., 2009a. Berberine suppresses in vitro migration and invasion of human SCC-4 tongue squamous cancer cells through the inhibitions of FAK, IKK, NF-kappaB, u-PA and MMP-2 and -9. Cancer Letters 279, 155-162. 
Ho, Y.T., Yang, J.S., Lu, C.C., Chiang, J.H., Li, T.C., Lin, J.J., Lai, K.C., Liao, C.L., Lin, J.G., Chung, J.G., 2009b. Berberine inhibits human tongue squamous carcinoma cancer tumor growth in a murine xenograft model. Phytomedicine 16, 887-890.

Hoshi, A., Ikekawa, T., Ikeda, Y., Shirakawa, S., Iigo, M., 1976. Antitumor activity of berberrubine derivatives. Gann 67, 321-325.

Hsu, W.H., Hsieh, Y..S., Kuo, H.C., Teng, C.Y., Huang, H.I., Wang, C. J., Yang S.F., Liou, Y.S., Kuo, W.H., 2007. Berberine induces apoptosis in SW620 human colonic carcinoma cells through generation of reactive oxygen species and activation of JNK/p38 MAPK and FasL. Archives of Toxicology 81, 719-728.

Huffman, J.W., Miller, E.G., 1960. New Synthetic Approach to the Berberine Alkaloids. Journal of Organic Chemistry 25, 90-92.

Hussain, S.P., Harris, C.C., 2007. Inflammation and cancer: an ancient link with novel potentials. International Journal of Cancer 121, 2372-2380.

Hwang, J.M., Kuo H.C., Tseng T.H., Liu J.Y., Chu C.Y., 2006. Berberine induces apoptosis through a mitochondria/caspases pathway in human hepatoma cells. Archives of Toxicology 80, 62-73.

Iizuka, N., Miyamoto, K., Okita, K., Tangoku, A., Hayashi, H., Yosino, S., Abe, T., Morioka, T., Hazama, S., Oka, M., 2000a. Inhibitory effect of Coptidis Rhizoma and berberine on the proliferation of human esophageal cancer cell lines. Cancer Letters 148, 19-25.

Iizuka, N., Miyamoto, K., Hazama, S., Yoshino, S., Yoshimura, K., Okita, K., Fukumoto, T., Yamamoto, S., Tangoku, A., Oka, M., 2000b. Anticachectic effects of Coptidis rhizoma, an antiinflammatory herb, on esophageal cancer cells that produce interleukin 6. Cancer Letters (Shannon, Ireland) 158, 35-41.

Iizuka, N., Oka, M., Yamamoto, K., Tangoku, A., Miyamoto, K., Miyamoto, T., Uchimura, S., Hamamoto, Y., Okita, K., 2003. Identification of common or distinct genes related to 
antitumor activities of a medicinal herb and its major component by oligonucleotide microarray. International Journal of Cancer 107, 666-672.

Inoue, K., Kulsum, U., Chowdhury, S. A., Fujisawa, S.I., Ishihara, M., Yokoe, I., Sakagami, H., 2005. Tumor-specific cytotoxicity and apoptosis-inducing activity of berberines. Anticancer Research 25(6B), 4053-4059.

Issat, T., Jakóbisiak, M., Golab, J., 2006. Berberine, a natural cholesterol reducing product, exerts antitumor cytostatic/cytotoxic effects independently from the mevalonate pathway. Oncology reports 16, 1273-1276.

Jagetia, G.C., Baliga, M.S., 2004. Effect of Alstonia scholaris in enhancing the anticancer activity of berberine in the Ehrlich ascites carcinoma-bearing mice. Journal of Medicinal Food 7, 235-244.

Jahnke, G.D., Price, C.J., Marr, M.C., Myers, C.B., George, J.D., 2006. Developmental toxicity evaluation of berberine in rats and mice. Birth Defects Research Part B: Developmental and Reproductive Toxicology 77, 195-206.

Jantova, S., L'ubos, C., Cernakova, M., Kost'alova, D., 2003. Effect of berberine on proliferation, cell cycle and apoptosis in HeLa and L1210 cells. Journal of Pharmacy and Pharmacology 55, 1143-1149.

Jantova, S., Cipak, L., Letašiová, S., 2007. Berberine induces apoptosis through a mitochondrial/caspase pathway in human promonocytic U937 cells. Toxicology in Vitro 21, 25-31.

Johannes, S.B., Rose, M.D., 1930. Pictet and Gams' berberine synthesis, Journal of the American Chemical Society 52, 660-664.

Kametani, T., Noguchi, I., Saito, K., Kaneda, S., 1969. Studies on the syntheses of heterocyclic compounds. CCCII. Alternative total syntheses of (+/-)-nandinine, (+/-)canadine, and berberine iodide. Journal of Chemical Society C: Organic 15, 2036-2038. 
Kang, J.X., Liu, J., Wang, J.D., He, C.W., Li, F.P., 2005. The extract of Huanglian, a medicinal herb, induces cell growth arrest and apoptosis by upregulation of interferon- $\beta$ and TNF- $\alpha$ in human breast cancer cells. Carcinogenesis 26, 1934-1939.

Katiyar, S.K., Meeran, S.M., Katiyar, N., Akhtar, S., 2009. p53 cooperates berberine-induced growth inhibition and apoptosis of non-small cell human lung cancer cells in vitro and tumor xenograft growth in vivo. Molecular Carcinogenesis 48, 24-37.

Kerr, L.E., Birse-Archbold, J.L., Short, D.M., McGregor, A.L., Heron, I., MacDonald, D.C., Thompson, J., Carlson, G.J., Kelly, J.S., McCulloch, J., Sharkey, J., 2007. Nucleophosmin is a novel Bax chaperone that regulates apoptotic cell death. Oncogene 26, 2554-2562.

Kettmann, V., Kostalova, D., Hoeltje, H.D., 2004a. Human topoisomerase I poisoning: docking protoberberines into a structure-based binding site model. Journal of ComputerAided Molecular Design 18, 785-796.

Kettmann, V., Kostalova, D., Jantova, S., Cernakova, M., Drimal, J., 2004b. In vitro cytotoxicity of berberine against HeLa and L1210 cancer cell lines. Pharmazie 59, 548-551.

Khin, M.U., Myo, K., Nyunt, N.W., Aye, K., Tin, U., 1985. Clinical trial of berberine in acute watery diarrhea. British Medical Journal (Clin Res Ed) 291, 1601-1605.

Kim, D.W., Ahan, S.H., Kim, T.Y., 2007. Enhancement of Arsenic Trioxide (As(2)O(3))Mediated Apoptosis Using Berberine in Human Neuroblastoma SH-SY5Y Cells. Journal of Korean Neurosurgical Society 42, 392-399.

Kim, S., Choi, J.H., Kim, J.B., Nam, S.J., Yang, J.H., Kim, J.H., Lee, J.E., 2008. Berberine suppresses TNF-alpha-induced MMP-9 and cell invasion through inhibition of AP-1 activity in MDA-MB-231 human breast cancer cells. Molecules 13, 2975-2985.

Kobayashi Y., Yamashita Y., Fuji N., Takaboshi K., Kawakami T., Kamwamura M., Mizukami T., Nakano H., 1995. Inhibitors of DNA topoisomerase I and II isolated from the Coptis rhizomes. Planta Medica 61, 414-418. 
Kong, W., Wei, J., Abidi, P., Lin, M., Inaba, S., Li, C., Wang, Y.L, Wang, Z.Z, Si, S.Y., Pan, H.N., Wang, S.K., Wu, J.D,. Wang, Y., Li, Z.R., Liu, J.W., Jiang, J.D., 2004. Berberine is a novel cholesterol-lowering drug working through a unique mechanism distinct from statins. Nature Medicine (New York, NY, United States) 10, 1344-1351.

Kowalewski, Z., Mrozikiewicz, A., Bobkiewicz, T., Drost, K., Hladon, B., 1975. Toxicity of berberine sulfate. Acta Poloniae Pharmaceutica 32, 113-120.

Kuo, C.L., Chi, C.W., Liu, T.Y., 2004. The antiinflammatory potential of berberine in vitro and in vivo. Cancer Letters (Amsterdam, Netherlands) 203, 127-137.

Kuo, C.L., Chi, C.W., Liu, T.Y., 2005. Modulation of apoptosis by berberine through inhibition of cyclooxygenase-2 and Mcl-1 expression in oral cancer cells. In Vivo 19(1, Spec. Iss.), 247-252.

Kyoko, H., Kazuki, M., Yasuo, N., Toshimitsu, H. and Shinichi, U., 2007. Antiviral activity of berberine and related compounds against human cytomegalovirus. Bioorganic \& Medicinal Chemistry Letters 17, 1562-1564.

Lee, C.H., Jeon, Y.T., Kim, S.H., Song, Y.S., 2007a. NF-kappaB as a potential molecular target for cancer therapy. Biofactors 29, 19-35.

Lee, C.H., Chen, J.C., Hsiang, C.Y., Wu, S.L., Ho, T.Y., 2007b. Berberine suppresses inflammatory agents-induced interleukin- $1 \mathrm{~b}$ and tumor necrosis factor- $\alpha$ productions via the inhibition of I $\kappa$ B degradation in human lung cells. Pharmacological Research 56, 193 201.

Leland, H.H., Michael, B.K., 1994. Cell Cycle Control and Cancer. Science 266, 1821-1828.

Lenka, G., Jirı', D.1., Radek, M., 2007. Quaternary protoberberine alkaloids. Phytochemistry $68,150-175$. 
Letašiová, S., Jantová, S., Múcková, M., Theiszová, M., 2005a. Antiproliferative activity of berberine in vitro and in vivo. Biomedical papers of the Medical Faculty of the University Palacký, Olomouc, Czechoslovakia 149, 461-463.

Letašiová, S., Jantova, S., Horvathova, M., Lakatos, B., 2005b. Toxicity and apoptosis induced by berberine-a potential anticancer drug. Biologia (Bratislava, Slovakia) 60 (Suppl. 17), 97-100.

Letašiová, S., Jantova, S., Cipak, L., Muckova, M., 2006. Berberine-antiproliferative activity in vitro and induction of apoptosis/necrosis of the U937 and B16 cells. Cancer Letters (Amsterdam, Netherlands) 239, 254-262.

Li, Bo, Zhu, W.L., Chen, K.X., 2008a. Advances in the study of berberine and its derivatives. Acta Pharmaceutica Sinica 43, 773-787. (Chinese)

Li, H., Guo, L., Jie, S., Liu, W., Zhu, J., Du, W., Fan, L., Wang, X., Fu, B., Huang, S., $2008 b$. Berberine inhibits SDF-1-induced AML cells and leukemic stem cells migration via regulation of SDF-1 level in bone marrow stromal cells. Biomedicine \& Pharmacotherapy $62,573-8$.

Li, X.K., Motwani, M.T., William, B., William, S., Gary, K.S., 2000. Huanglian, a Chinese herbal extract, inhibits cell growth by suppressing the expression of cyclin B1 and inhibiting CDC2 kinase activity in human cancer cells. Molecular Pharmacology 58, 12871293.

Liao, H.M., Yang, Y.Q., Bai, J.L., 2003. A survey of therapeutic and adjunctional effects of Chinese medicines on tumours. Xi Zang Ke Ji 8, 42-43. (Chinese)

Lin, C.C., Ng, L.T., Hsu, F. F., Shieh, D.E., Chiang, L.C., 2004a. Cytotoxic effects of Coptis chinensis and Epimedium sagittatum extracts and their major constituents (berberine, coptisine and icariin) on hepatoma and leukaemia cell growth. Clinical and Experimental Pharmacology and Physiology 31(1/2), 65-69. 
Lin, C.C., Kao, S.T., Kao, S.T., Chen, G. W., Chung, J.G., 2005. Berberine decreased Nacetylation of 2-aminofluorene through inhibition of $\mathrm{N}$-acetyltransferase gene expression in human leukemia HL-60 cells. Anticancer Research 25, 4149-4155.

Lin, C.C., Kao, S.T., Chen, G.W., Ho, H.C., Chung J.G., 2006a. Apoptosis of human leukemia HL-60 cells and murine leukemia WEHI-3 cells induced by berberine through the activation of caspase-3. Anticancer Research 26, 227-242.

Lin, C.C., Lin, S.Y., Chung, J.G., Lin, J.P., Chen, G.W., Kao, S.T., 2006b. Downregulation of cyclin B1 and upregulation of Wee1 by berberine promotes entry of leukemia cells into the $\mathrm{G}_{2} / \mathrm{M}$ phase of the cell cycle. Anticancer Research 26, 1097-1104.

Lin, C.C., Yang, J.S., Chen, J.T., Fan, S., Yu, F.S., Yang, J.L., Lu, C.C., Kao, M.C., Huang, A.C., Lu,H.F., Chung, J.G., 2007a. Berberine induces apoptosis in human HSC-3 oral cancer cells via simultaneous activation of the death receptor-mediated and mitochondrial pathway. Anticancer Research 27, 3371-3378.

Lin, H.L., Liu, T.Y., Wu, C.W., Chi, C.W., 1999. Berberine modulates expression of mdr1 gene product and the responses of digestive track cancer cells to Paclitaxel. British Journal of Cancer 81, 416-22.

Lin, J.P., Yang, J.S., Lee, J.H., Hsieh, W.T., Chung, J.G., 2006c. Berberine induces cell cycle arrest and apoptosis in human gastric carcinoma SNU-5 cell line. World Journal of Gastroenterology 12, 21-28.

Lin, J.P., Yang, J.S., Chang, N.W., Chiu, T.H., Su, C.C., Lu, K.W., Ho, Y.T., Yeh, C.C., Mei, D.Y., Lin, H.J., Chung, J.G., 2007b. GADD153 mediates berberine-induced apoptosis in human cervical cancer Ca ski cells. Anticancer Research 27(5A), 3379-86.

Lin, J.P., Yang, J. S., Wu, C.C., Lin, S.S., Hsieh, W.T., Lin, M.L., Yu, F.S., Yu, C.S., Chen, G.W., Chang, Y.H., Chung, J.G., 2008. Berberine induced down-regulation of matrix 
metalloproteinase-1, -2 and -9 in human gastric cancer cells (SNU-5) in vitro. In Vivo 22, 223-230.

Lin, S.K., Tsai, S.C., Lee, C.C., Wang, B.W., Liou, J.Y., Shyu, K.G., 2004b. Berberine inhibits HIF-1 $\alpha$ expression via enhanced proteolysis. Molecular Pharmacology 66, 612-619.

Lin, T.H., Kuo, H.C., Chou, F.P., Lu, F.J., 2008. Berberine enhances inhibition of glioma tumor cell migration and invasiveness mediated by arsenic trioxide. BMC Cancer 8, 58.

Liu, Z., Liu, Q., Xu, B., Wu, J., Guo, C., Zhu, F., Yang, Q., Gao, G., Gong, Y., Shao, C., 2009a. Berberine induces p53-dependent cell cycle arrest and apoptosis of human osteosarcoma cells by inflicting DNA damage. Mutation Research 662, 75-83.

Liu, J., He, C., Zhou, K., Wang, J., Kang, J.X., 2009b. Coptis extracts enhance the anticancer effect of estrogen receptor antagonists on human breast cancer cells. Biochemical and Biophysical Research Communications 378, 174-178.

Lloyd, J.U. and Lloyd, C.G., 1887. In: Drugs and Medicines of North America, 1884-1887: Coptis Trifolia. Gold-thread. http://www.henriettesherbal.com/eclectic/dmna/coptis.html. Visiting time: May, 2009.

Lu, H., Ouyang, W., Huang, C., 2006. Inflammation, a key event in cancer development. Molecular Cancer Research 4, 221-233.

Luo, W.Q., Feng, Y.B., 2004. Clinical study of Chinese herbs on adenoma of large intestine and its cancer. Journal of Traditional Chinese Medicine 45, 78-79.

Luo, W.Q., Hui, S.C., Chan, T.Y., Feng, Y., 2002. Inhibitory effect of water extract from golden thread (Huanglian) on Leukemia L-1210 cells cultured in vitro. Pharmacologist (USA) 44, 126.

Maiguel, D.A., Jones, L., Chakravarty, D., Yang, C., Carrier, F., 2004. Nucleophosmin sets a threshold for p53 response to UV radiation. Molecular Cell Biology 24, 3703-3711. 
Mantena, S.K., Sharma, S.D., Katiyar, S.K., 2006a. Berberine, a natural product, induces G1phase cell cycle arrest and caspase-3-dependent apoptosis in human prostate carcinoma cells. Molecular Cancer Therapeutics 5, 296-308.

Mantena, S.K., Som, D.S., Santosh, K.K., 2006b. Berberine inhibits growth, induces G1 arrest and apoptosis in human epidermoid carcinoma A431 cells by regulating Cdki-Cdk-cyclin cascade, disruption of mitochondrial membrane potential and cleavage of caspase 3 and PARP. Carcinogenesis 27, 2018-2027.

Mantovani, A., Balkwill, F., 2006. RalB signaling: a bridge between inflammation and cancer. Cell 127, 157-170.

McCullough, K.D., Martindale, J.L., Klotz, L.O., Aw, T.Y., Holbrook, N.J., 2001. Gadd153 sensitizes cells to endoplasmic reticulum stress by down-regulating $\mathrm{Bcl} 2$ and perturbing the cellular redox state. Molecular and Cellular Biology 21, 1249-59.

Meeran, S.M., Katiyar, S., Katiyar, S.K. 2008. Berberine-induced apoptosis in human prostate cancer cells is initiated by reactive oxygen species generation. Toxicology and Applied Pharmacology 229, 33-43.

Narasimhan, S., Nair, G.M., 2005. Cytotoxic effect of Coscinium fenestratum (Gaertn.) Colebr. And its active principle berberine on L929 cells. Medicinal Chemistry Research 14, 118-124.

Ohta, Y., Kongo-Nishimura, M., Hayashi, T., Kishikawa, T., 2004. Effect of Oren-gedoku-to (Huanglian-Jie-Du-Tang) extract on disruption of hepatic antioxidant defense systems in rats treated with galactosamine. Journal of Ethnopharmacology 94, 323-329.

Pandey, M.K., Sung, B., Kunnumakkara, A.B., Sethi, G., Chaturvedi, M.M., Aggarwal, B.B., 2008. Berberine modifies cysteine 179 of IkappaBalpha kinase, suppresses nuclear factorkappaB-regulated antiapoptotic gene products, and potentiates apoptosis. Cancer Research $68,5370-5379$. 
Patricia, S.W., Hoshi, A., Ikekawa, T., Ikeda, Y., Shirakawa, S., Iigo, M., 2002. History of Hoxsey Treatment. http://www.tldp.com/issue/166/166hoxs.htm. Visiting time: May, 2009.

Peng, P.L., Hsieh, Y.S., Wang, C.J., Hsu, J.L., Chou, F.P., 2006. Inhibitory effect of berberine on the invasion of human lung cancer cells via decreased productions of urokinaseplasminogen activator and matrix metalloproteinase-2. Toxicology and Applied Pharmacology 214, 8-15.

Peng, P.L., Kuo, W.H., Tseng, H.C., Chou, F.P., 2008. Synergistic tumor-killing effect of radiation and berberine combined treatment in lung cancer: the contribution of autophagic cell death. International Journal of Radiation Oncology, Biology, Physics 70, 529-42.

Qian, B.W., 1980. Syndrome differentiation and treatment for tumour (Zhong Liu De Bian Zhen Lun Zhi). Shanghai Science and Technology Press, Shanghai, pp. 81. (Chinese)

Qiu, J., 2007. 'Back to the future' for Chinese herbal medicines. Nature Reviews Drug Discovery 6, 506-507.

Qiu, S.H., Tang, H.B., Li, F.Y., Xiao, J.R., Chen, B.Y., 2004a. Experimental study of the acute toxicity on common-used bitter and cold medicines. Central South Pharmacy 2, 37-38. (Chinese)

Qiu, S.H., Li, F.Y., Yin, J.K., Wu, H.J., Xiao, J.R., 2004b. An experimental study on the effects of nine medicinal herbs with the properties of bitterness and cold on gastrointestinal movement and hepatorenal function of mice. Journal of Hunan University of Traditional Chinese Medicine 24, 1-6. (Chinese)

Rabbani, G.H., Butler, T., Knight, J., Sanyal, S.C., Alam, K., 1987. Randomized controlled trial of berberine sulfate therapy for diarrhea due to enterotoxigenic E. coli and Vibrio cholerae. Journal of Infectious Diseases 155, 979-984.

Registry of the Toxic Effects of Chemical Substances. 1998. Berberine. RTECS database: DR987000. Accessed December 22, 2008. 
Reed, C.J., 2002. Apoptosis-based therapies. Nature Reviews Drug Discovery 1, 111-121.

Rojsanga, P., Mugdha, S., Gritsanapan, W., Seung, J.B., 2007. Berberine, a natural isoquinoline alkaloid, induces NAG-1 and ATF3 expression in human colorectal cancer cells. Cancer Letters 258, 230-240.

Sabir, M., Bhide, N.K., 1971. Study of some pharmacological actions of berberine. Indian Journal of Physiology and Pharmacology 15, 111-32.

Sato, F., Hashimoto, T., Hachiya, A., Tamura, K.I., Choi, K.B., Morishige, T., Fujimoto, H., Yamada, Y., 2001. Metabolic engineering of plant alkaloid biosynthesis. Proceedings of the National Academy of Sciences of the United States of America 98, 367-372.

Society of Japanese Pharmacopoeia, 2001. Coptis Rhizome. In: Japanese pharmacopoeia (English version), $14^{\text {th }}$ edition. Junkudo Book Shop, Tokyo, pp. 901-902.

Stermitz, F.R., Peter, L., Jeanne, N.T., Lauren, A.Z., Kim, L., 2000. Synergy in a medicinal plant: Antimicrobial action of berberine potentiated by $5^{\prime}-$ methoxyhydnocarpin, a multidrug pump inhibitor. Proceedings of the National Academy of Sciences of the United States of America 97, 1433-1437.

Subbaiah, T.V., Amin, A.H., 1967. Effect of berberine sulphate on Entamoeba histolytica, Nature 215, 527-528.

Subhuti, D., 2005. In: New Uses of Berberine: A Valuable Alkaloid from Herbs for "DampHeat" Syndromes, http://www.itmonline.org/arts/berberine.htm. Visiting time: May, 2009.

Sun, J., Wen, Q.H., Song, Y., Li, X., Jing, J., Ma, J.S., Zhou, Q.L., 2006. Study on antitumor activities of Huanglian Jiedu decoction. China Journal of Chinese Materia Medica 17, 1461-1463. (Chinese)

Tan, Y.L., David, G., Eng, S.O., 2006. Investigation of differentially expressed proteins due to the inhibitory effects of berberine in human liver cancer cell line HepG2. Molecular BioSystems 2, 250-258. 
The State Pharmacopoeia Commission of the P.R. China, 2005. Pharmacopoeia of The People's Republic of China (Chinese Edition 2005). Volume 1, Huanglian. Chemical Industry Press, Beijing, pp. 213-214. (Chinese)

Thirupurasundari, C.J., Padmini, R., Devaraj, S.N., 2009. Effect of berberine on the antioxidant status, ultrastructural modifications and protein bound carbohydrates in azoxymethane-induced colon cancer in rats. Chemico-Biological Interactions 177, 190-195.

Tsang C.M., Lau Echo P.W., Di K., Cheung P.Y., Hau P.M., Ching Y.P., Wong Y.W., Cheung Annie L.M., Wan Thomas S.K., Tong Y, Tsao S.W., Feng Y., 2009. Berberine inhibits RhoGTPases and cell migration at low doses but induces G2 arrest and apoptosis at high doses in human cancer cells. International Journal of Molecular Medicine. 24:131-138. Tse, W.K., 1977. Anticancer Chinese herbs (Kang Ai Zhong Cai Yao). Xing Hua Tu Shu Gong Si, Hong Kong, p.150. (Chinese)

Wang, D.Y., Yeh, C.C., Lee, J.H., Hung, C.F., Chung J.G., 2002. Berberine inhibited arylamine $N$-acetyltransferase activity and gene expression and DNA adduct formation in human malignant astrocytoma (G9T/VGH) and brain glioblastoma multiforms (GBM 8401) cells. Neurochemical Research 27, 883-889.

Wang, S.S., Zheng, Z.G., Weng, Y.Q., Yu, Y.J., Zhang, D.F., Fan, W.H., Dai, R.H., Hu, Z.B., 2004. Angiogenesis and anti-angiogenesis activity of Chinese medicinal herbal extracts. Life Sciences 74, 2467-2478.

Wang, X.N., Han, X., Xu, L.N., Yin, L.H., Xu, Y.W., Qi, Y., Peng, J.Y., 2008. Enhancement of apoptosis of human hepatocellular carcinoma SMMC-7721 cells through synergy of berberine and evodiamine. Phytomedicine 15, 1062-1068.

Wu, H.L., Hsu, C.Y., Liu, W.H., Benjamin, Y.M.Y., 1999. Berberine-induced apoptosis of human leukemia HL-60 cells is associated with down-regulation of nucleophosmin/B23 and telomerase activity. International Journal of Cancer 81, 923-929. 
Wu, P., Sun, X.Y., Sun F.J., 1982. Shen Nong's Herbal Classic. People's Health Press, Beijing, China, pp. 26. (Chinese)

Xu, G.J., Wang Q., 1997. Coloured illustrations of antitumour Chinese traditional and herbal drugs (Cai Tu Kang Ai Zhong Cai Yao). Fujian Science and Technology Press, Fuzhou, China, pp. 1121. (Chinese)

Xu, J.T., Wang, L.Q., Xu B., 2004. Research Development of Coptis Chinensis. Acta Academiae Medicinae Sinicae 26, 704-707. (Chinese)

Yang, S.Y., Gao, X.S., 1996. The research survey of the newborn jaundice induced and enhanced by Huanglian. China Journal of Chinese Materia Medica 21, 187-188. (Chinese)

Ye, X., Feng Y., Tong Y., Ng K.M., Tsao S.W., Laud G.K.K., Sze C.W., Zhang Y.B., Tang J., Shen J.G., Kobayashi S., 2009. Hepatoprotective effects of Coptidis Rhizoma aqueous extract on carbon tetrachloride-induced acute liver hepatotoxicity in rats. Journal of Ethnopharmacology. 124, 130-136.

Yu, F.S., Yang, J.S., Lin, H.J., Yu, C.S., Tan, T.W., Lin, Y.T., Lin, C.C., Lu, H.F., Chung J.G., 2007. Berberine inhibits WEHI-3 leukemia cells in vivo. In Vivo 21, 407-412.

Yu, Y.Y., Wang, B.C., Peng, L., Wang, J.B., Zeng, C., 2006. Advances in pharmacological studies of Coptis Chinensis. Journal of Chongqing University (Natural Science Edition) 29, 107-111. (Chinese)

Zhang, W.J., Ou, T.M., Lu, Y.J., Huang, Y.Y., Wu, W.B., Huang, Z.S., Zhou, J.L., Wong, K.Y., Gu, L.Q., 2007. 9-Substituted berberine derivatives as G-quadruplex stabilizing ligands in telomeric DNA. Bioorganic \& Medicinal Chemistry 15, 5493-5501.

Zhou, H., Mineshita, S., 2000. The effect of berberine chloride on experimental colitis in rats in vivo and in vitro. Journal of Pharmacology and Experimental Therapeutics 294, 822-829. 
Zhou, L., Yang, Y., Wang, X., Liu, S., Shang, W., Yuan, G., Li, F., Tang, J., Chen, M., Chen, J., 2007. Berberine stimulates glucose transport through a mechanism distinct from insulin. Metabolism 56, 405-12.

Zuo, F., Nakamura, N., Akao, T., Hattori, M., 2006. Pharmacokinetics of berberine and its main metabolites in conventional and pseudo germ-free rats determined by liquid chromatography/ion trap mass spectrometry. Drug Metabolism and Disposition 34, 20642072. 


\section{Figure captions}

Fig. 1 The structures of berberine and other key protoberberine-type alkaloids contained in Huanglian

Fig. 2 The natural habitat and cultivation of Huanglian (Coptis chinensis Franch.) in two famous endemic regions in China. Upper panel (pictures kindly provided by government of Shizu county of Chongqing city): A. An exhibition board showed the GAP authorized field for Huanglian cultivation in Shizu county of Chongqing city, and this board indicated the area has been certificated by the SFDA (state food and drug administration) of China for the cultivation and production of the official Huanglian, whose quality and safety can be guaranteed. The area with a exhibition board also plays an important role in the promotion, guidance, and paradigm of the herb cultivation in other appropriate areas; B. one GAP base for Huanglian cultivation, which demonstrated that ecological conditions should be humid, cool, shadowed, at high altitude around 1500-2300 m sea level and with high organic and weak acidic soil; C. A photo of one single plant of Huanglian taken in April. Lower panel (photo taken by ourselves): a. An exhibition board showed the GAP authorized field for Huanglian cultivation in Lichuan county of Hubei Province; b. A GAP base for Huanglian cultivation, with the same conditions as B; c. A photo of one single plant of Huanglian taken in April.

Fig. 3 A schematic diagram of molecular machinery for antineoplastic properties of berberine. Berberine has multiple anticancer effects through direct cell toxicity, anti-proliferation and anti-invasion pathways. Bold arrows with number 1,2, 3, 4, 5 and 6 show the different cell signaling pathways targeted by berberine. $\rightarrow$ : stimulation or positive regulation; $\rightarrow \rightarrow$ : not yet 
completely demonstrated action; $\perp$ : inhibition. 1. Cdki-Cdk-cyclin cascade; 2 . Mitochondrial/caspase-dependent pathway; 3. Fas/FasL signaling pathway; 4. DNA damage via topoisomerase I inhibition, and followed by p53 pathway in response; 5. NF-кB pathway; 6. RhoA GTPase/NF-кB pathway 
Figure 1.<smiles>COc1ccc2cc3[n+](cc2c1OC)CCc1cc2c(cc1-3)OCO2</smiles>

Berberine<smiles></smiles>

Coptisine<smiles>Cc1c2[n+](cc3c4c(ccc13)OCO4)CCc1cc3c(cc1-2)OCO3</smiles>

Worenine<smiles>COc1cc2c(cc1OC)-c1cc3ccc4c(c3c[n+]1CC2)OCO4</smiles>

Epiberberine Jatrorrhizine Palmatine 
Tang et al., Fig. 2

Figure 2.
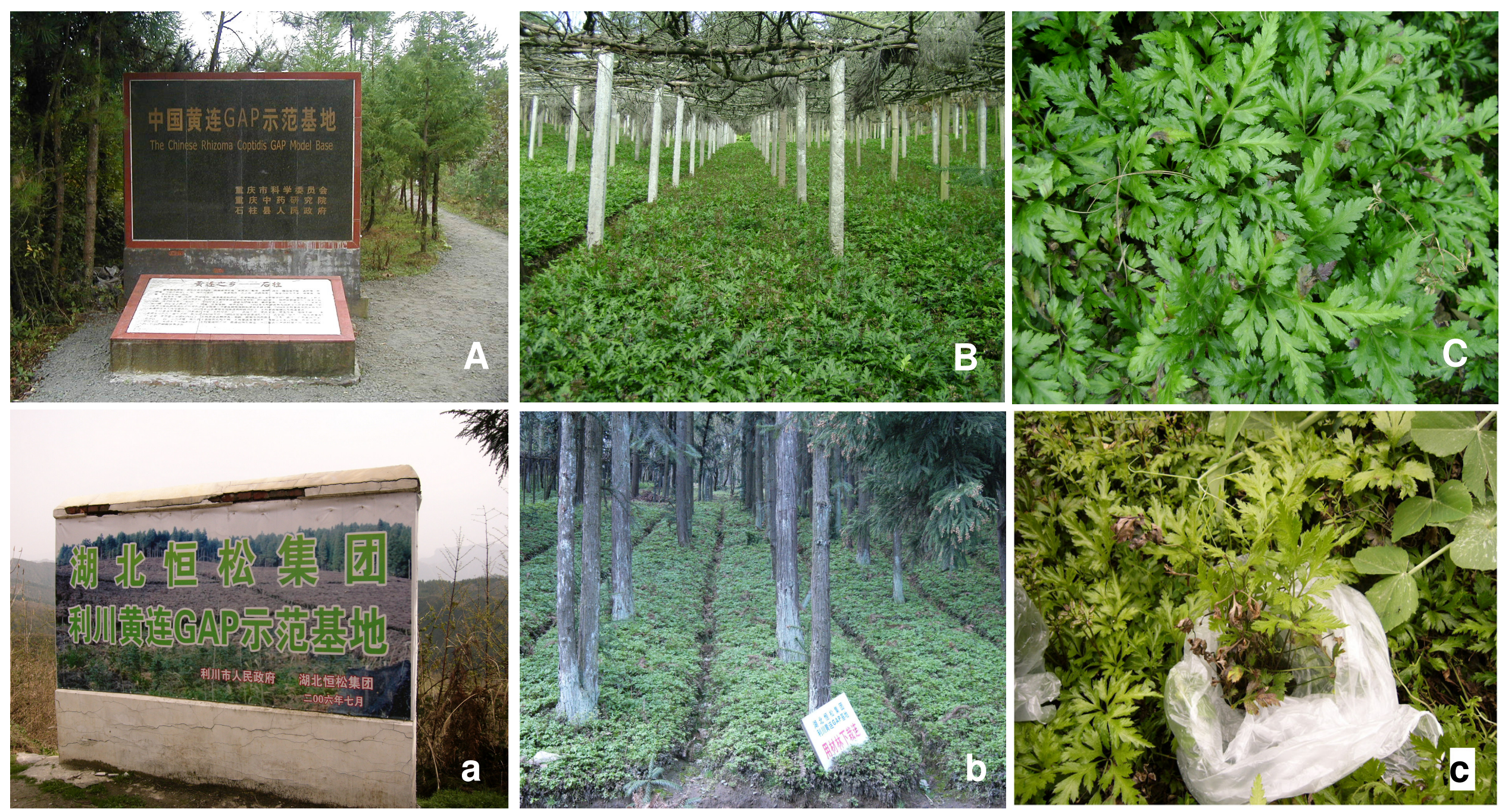
Figure 3.

\section{Berberine derived from Huanglian}

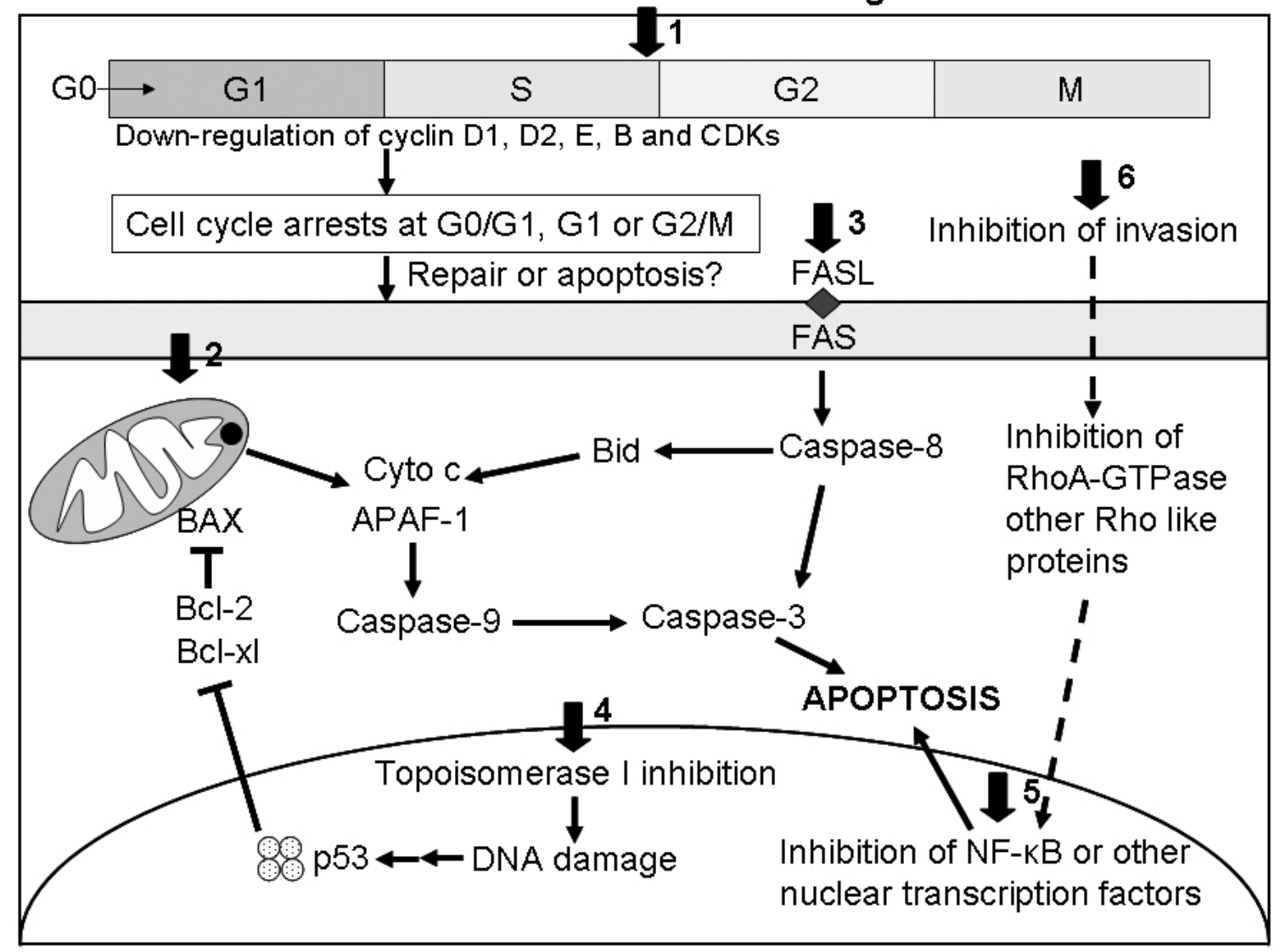

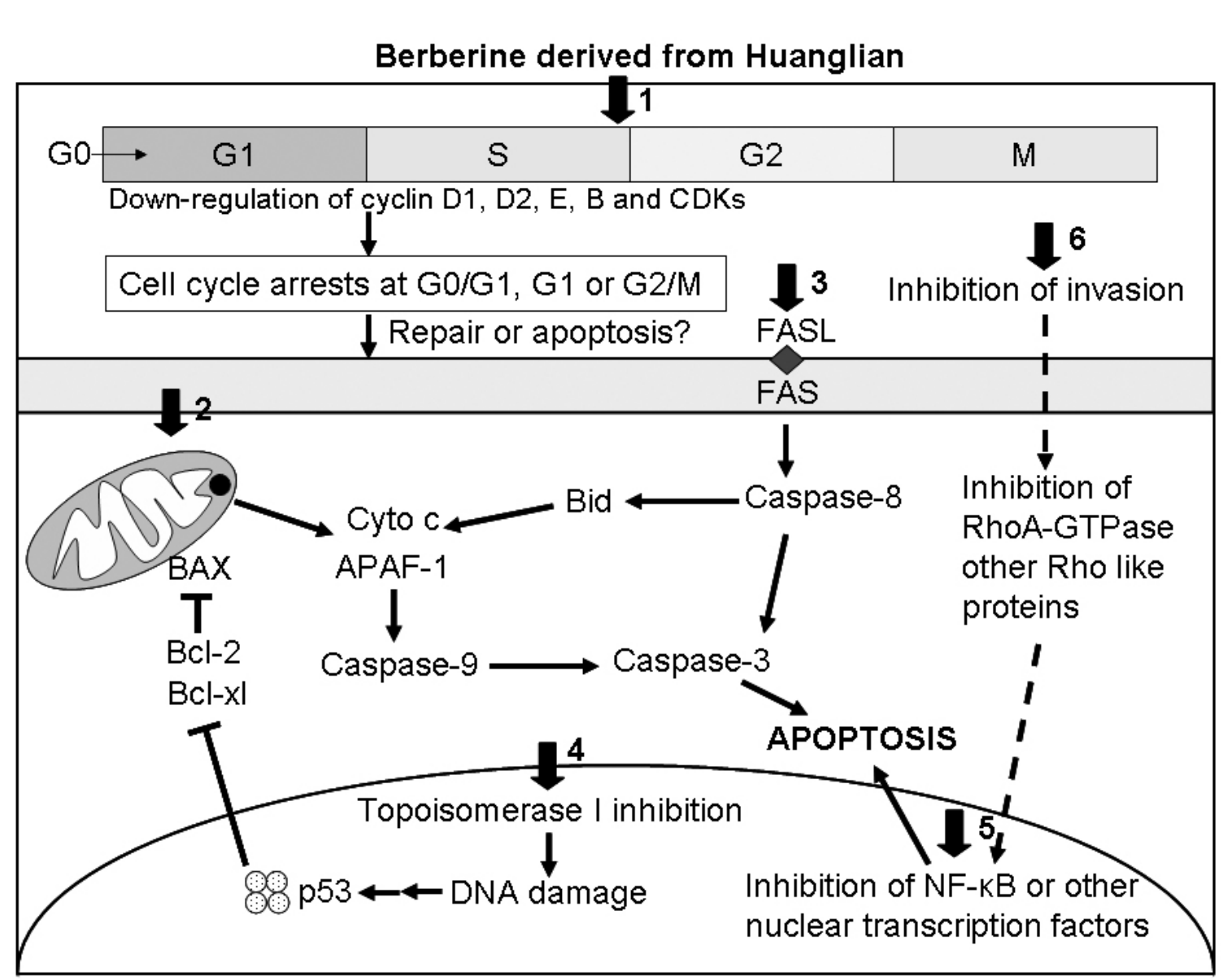

